\title{
Khal Torabully, Yanick Lahens oder die Konvivenz auf den Archipelen von Natur und Kultur
}

Wie Vargas Llosa aus dem Standpunkt der vierten Phase beschleunigter Globalisierung zunächst auf die dritte Phase und deren Exklusionen blickte, entfaltet der 1956 in Port-Louis auf Mauritius als Sohn eines Seemans aus Trinidad und einer aus Indien stammenden Mutter geborene Dichter, Filmemacher und Kulturtheoretiker Khal Torabully ${ }^{1}$ seit den achtziger Jahren sein Projekt der „Coolitude“. Mit ihm versucht er, eine weltumspannende Poetik auf Grundlage der Inklusion all jener von der Geschichte Ausgeschlossenen zu entwickeln, die sich zumeist unter elenden Umständen als Lohn- und Kontraktarbeiter weltweit verdingen mussten. Dies ist ein in vielerlei Hinsicht noch im Zeichen der Postmoderne stehendes Vorhaben, in welchem die Stimmen der bislang Verschwiegenen, Untergetauchten, all jener also, die im Sinne Lezama Limas innerhalb des „sumergido“ anzusiedeln sind, zu Gehör gebracht werden sollen.

Zugleich werden in diesem literarischen Vorhaben aber auch Teile dessen sichtbar, was sich fraglos nach den Literaturen im Zeichen der Postmoderne ansiedelt. Gewiss ist es aus heutiger Perspektive schwer auszuloten, wie diese nachpostmodernen Ästhetiken beschaffen sein werden. Aussagen hierüber sind genuin risikobehaftet. Doch möchte ich in unserer Vorlesung gerne dieses Risiko eingehen, da uns die Arbeit an derlei Fragen tief in die prospektiven Dimensionen literarischen Schaffens führt. Denn die vierte Phase beschleunigter Globalisierung ist nach dem Zeugnis der Literaturen der Welt, aber selbstverständlich auch nach vielen politischen, sozialen und ökonomischen Indikatoren im vergangenen zweiten Jahrzehnt des 21. Jahrhunderts zu Ende gegangen. Und ebenso hat auch die Phase jener Literaturen im Zeichen der Postmoderne ihren Abschluss gefunden, mit deren Ausbildung und Entwicklung wir uns ausführlich in unserer Vorlesung beschäftigt und auseinandergesetzt haben.

Noch lassen sich aus einer wie auch immer gearteten historischen Distanz jene Prozesse nicht überblicken, in denen wir derzeit buchstäblich ,stecken'. In jedem Fall aber sind die literarhistorischen und literarästhetischen Übergänge zwischen postmodernen und nachpostmodernen Orientierungen, denen wir uns jetzt zuwenden wollen, in keiner Weise bruchartig, sondern fließend. Die fließenden, schleifenden Schnitte zwischen postmodernen und nachpostmodernen

1 Zum Werk von Khal Torabully vgl. Bragard, Véronique: Transoceanic Dialogues: Coolitude in Caribbean and Indian Ocean Literatures. Frankfurt am Main - Berlin - New York: Peter Lang 2008.

Ә Open Access. (C) 2021 Ottmar Ette, publiziert von De Gruyter. (c) BY-NC-ND Dieses Werk ist lizensiert unter einer Creative Commons Namensnennung - Nicht-kommerziell - Keine Bearbeitung 4.0 International Lizenz. https://doi.org/10.1515/9783110703450-039 
Ästhetiken ließen sich ohne jeden Zweifel vergleichen mit den Übergängen vom hispanoamerikanischen Modernismus zum Postmodernismus oder auch zwischen den Ästhetiken der Moderne und jenen der Postmoderne. Denn an dieser Stelle schließt sich der Kreis unserer Vorlesung, hatten wir doch mit Enrique VilaMatas Sichtweisen der historischen Avantgarden aus einer Sensibilität heraus eingesetzt vorgefunden, welche bereits unverkennbar postmodern geprägt war. Nun wollen wir abschließend vorsichtig die Konturen dessen ertasten, was sich nach der Ludizität und Luzidität eines Enrique Vila-Matas anschließen und eröffnen könnte.

Khal Torabullys Projekt gibt jenen „Coolies“ eine Stimme, deren Verbreitung über große Teile unseres Planeten im Kontext der dritten Phase beschleunigter Globalisierung vonstattengegangen war, innerhalb desselben kapitalistischen und vorwiegend angelsächsisch geprägten Weltwirtschaftssystems also, das in Mario Vargas Llosas Roman so konzentriert wie dicht dargestellt und nacherlebbar gemacht worden ist. Und doch war von diesen so zahlreichen Coolies, die vielerorts die Nachfolge der Sklaven innerhalb eines an der Oberfläche modernisierten, aber nicht grundlegend transformierten Wirtschaftssystems angetreten hatten, bestenfalls marginal die Rede gewesen. Es geht bei Torabully also weder um die schwarzen Sklaven, deren Versklavung zumindest legal im Verlauf eines langen 19. Jahrhunderts abgeschafft wurde, noch um die unter Sklavereiähnlichen Bedingungen ausgebeuteten Kautschukarbeiter, die größtenteils den indigenen Gruppen am Kongo oder Putumayo zur Zwangsarbeit ,entnommen' und zwangsrekrutiert wurden. Es geht vielmehr um eine Gruppe, für die sich während der dritten Phase beschleunigter Globalisierung vielleicht kein anderer mit literarischen wie photographischen Mitteln so sehr eingesetzt hat wie der transarchipelisch schreibende und lebende Lafcadio Hearn. ${ }^{2}$

Allerdings tauchen auch in Vargas Llosas Roman am Rande kleinere Gruppen aus entfernteren Regionen herangeführter Lohnarbeiter auf, denen die bei der Anwerbung versprochene kostenlose Rückfahrt etwa nach Barbados oder Trinidad nicht gewährt wird. Ein derartiges Schicksal, eine derartige Lebenserfahrung wird zum historischen Ausgangspunkt des Konzepts der Coolitude, bilden doch erste Migrationen - etwa von Indien auf die Antillen - nicht selten den Beginn weiterer, sich anschließender Migrationen innerhalb des weiten Gürtels der von den Kolonialmächten beherrschten Tropen. Es ist aus heutiger Sicht eigenartig zu sehen, wie wenig zeitgenössische Autorinnen und Autoren diese riesige Gruppe von Migrantinnen und Transmigranten zum literarischen Thema machten.

2 Zum Schreiben dieses Autors vgl. Ette, Ottmar: TransArea. Eine literarische Globalisierungsgeschichte, S. 204-218. 
Der 1956 geborene Khal Torabully ist in seiner Biographie ein sich zwischen Wissenschaft und Literatur, aber auch anderen künstlerischen Medien hin und her bewegender Autor, der aus diesen ständigen Perspektivwechseln viel für seine literarische Arbeit an ästhetischem Mehrwert erschloss. Der mit einer Arbeit über die Semiologie des Poetischen in Lyon promovierte Schriftsteller wurde auf der Insel Mauritius geboren und wuchs entsprechend vielsprachig zwischen europäischen und asiatischen Sprachen auf. Er war Gründungsmitglied einer französischen Forschergruppe über Globalisierung (Groupe d'Etudes et de Recherches sur les Globalisations, GERM) und beschäftigte sich daher auch wissenschaftlich mit Phänomenen der „Mondialisation“.

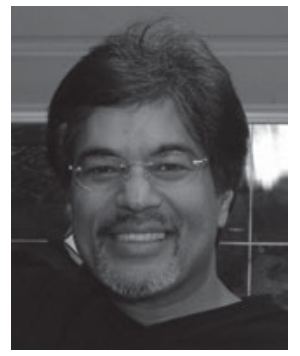

Abb. 128: Khal Torabully (Port Louis, Mauritius, 1956).

Geradezu selbstverständlich ist das literarische Oeuvre dieses Schriftstellers vor dem Hintergrund seiner Herkunft translingual angelegt und bewegt sich hauptsächlich zwischen den Literatursprachen des Englischen und des Französischen, wobei in sein Schreiben immer wieder Bruchstücke anderer Sprachen hineinragen. In seinen poetischen wie poetologischen Texten hat Khal Torabully den vorwiegend aus Indien, aber auch aus China und anderen Ländern stammenden Coolies nicht nur ein literarisches Denkmal, gleichsam einen Gedächtnisort, setzen wollen, sondern auch eine Poetik globaler Migration entfaltet, wie sie bereits in seinem 1992 erschienenen Band Cale d'Etoiles - Coolitude zum Ausdruck kommt:

Coolitude, um den ersten Stein meines Gedächtnisses allen Gedächtnisses zu legen, meine Sprache aller Sprachen, meinen Teil des Unbekannten, den zahlreiche Körper und zahlreiche Geschichten immer wieder in meinen Genen und in meinen Inseln hinterlegt haben. Dies ist der Gesang meiner Liebe zum Meer und zur Reise, die Odyssee, welche meine zur See fahrenden Völker noch nicht geschrieben haben ... und meine Mannschaft wird im Namen derer auftreten, welche die Grenzen auslöschen, um das Land des Menschen zu vergrößern. ${ }^{3}$

3 Torabully, Khal: Cale d'Etoiles - Coolitude. Saint-Denis de La Réunion: Azalées éditions 1992, S. 7. 
Es ist der Gesang eines Dichters, der in diesen Passagen ertönt und das Projekt einer Welt entfaltet, in welcher die Coolies ihre eigene Gegenwart und Präsenz, ihre eigene Würde und ihre eigenen transkulturellen Bindungen haben und entwickeln. So zeigt sich von Beginn dieses Textes an eine stark prospektive Dimension, welche die zukünftigen kulturellen Landschaften der Welt zu verändern sucht. Denn es geht dem aus einer einst aus Indien nach Mauritius gekommenen Familie stammenden Poeta doctus nicht um eine abgeschlossene Vergangenheit, die mit homerischen Anklängen evoziert würde. Ausgehend von jenen kollektiven wie individuellen Erfahrungen, welche die weitgehend entrechteten Lohn- und Kontraktarbeiter insbesondere in der dritten Phase beschleunigter Globalisierung erdulden mussten, wird eine auf Zukunft gestellte und die vierte Beschleunigungsphase der Globalisierung mit ihren Migrationen neu beleuchtende Poetik entwickelt, die sich schon früh in ihrer globalen Relationalität gerade im Bereich der Tropen äußert. Denn das lyrische Ich wendet sich an alle „aus Goa, aus Pondicheri, aus Chandernagor, aus / Cocame, aus Delhi, aus Surat, aus London, aus Shanghai, / aus Lorient, aus Saint-Malo“4 und entfaltet damit eine weltumspannende Kartographie nicht der Flächen und Kontinente, sondern der Häfen, der Inseln und der Archipele, welche miteinander diskontinuierlich verbunden sind.

Indien, China und Ozeanien werden mit den Häfen Europas verbunden und über diese transatlantisch mit den Inseln der Neuen Welt so verknüpft, wie die Coolies innerhalb der britischen und französischen Kolonialreiche auf die Plantagen im Pazifik wie im Atlantik, insbesondere in die englische und französische Karibik, verfrachtet wurden. Torabullys Text führt vor Augen, dass in jedem Transfer stets eine Transformation enthalten ist, die das Ich zu einem anderen macht und dabei immer neue Spielräume und Blickwinkel eröffnet, so als wollte man eine Landschaft kubistisch, aus verschiedenen Perspektiven zugleich, betrachten. Der Ozean wird zum verbindenden und zugleich trennenden Element, das auch die Städte dieses Netzwerks kolonialer Ausbeutung in Inseln verwandelt, die ihren eigenen ,angle“, ihre eigene Perspektive entfalten. Eine bewegungsgeschichtliche Sichtweise unseres Planeten gewinnt Form und Raum: Es ist nicht länger die der Imperien, der Reiche und der Weltherrschaft, sondern eine Geschichte der Wege, der Migrationen und Transmigrationen, welche unseren Planeten nicht länger in Blöcke massiv zentralisierter Herrschaft, sondern in Archipele migratorischer Relationen verwandelt. An die Stelle imperialer Raumgeschichte tritt eine Bewegungsgeschichte, die all jenen Bewegungen Gehör verschafft, die unterhalb der großen kontinentalen Einflusssphären verschwanden

4 Vgl Torabully, Khal: Cale d'étoiles - Coolitude, S. 89. 
und überspült waren - ganz in jenem Sinne, den schon José Lezama Lima in La expresión americana dem Amerikanischen verlieh. Denn dieses verstand er nicht als homogene Fläche im Sinne einer Geschichte dieses Raumes, sondern als weltumspannende Bewegung, welche ihre diskontinuierlichen Relationen, aber gerade auch das längst Überspülte, „lo sumergido“, wieder hervorspült und zum Vorschein bringt.

In seinem 1999 vorgelegten Gedichtband Chair Corail, Fragments Coolies (Korallenfleisch, Coolie Fragmente) ${ }^{5}$ hat der mauritianische Dichter, der im Übrigen auch als Filmemacher hervorgetreten ist und beim Internationalen Filmfestival von Cairo für La Mémoire maritime des Arabes 2010 mit dem Golden Award ausgezeichnet wurde, eine nicht wie bei Deleuze und Guattari am Rhizom, ${ }^{6}$ sondern an der Koralle ausgerichtete Metaphorologie eingeführt. Sie folgt diesem symbiotischen Lebewesen des Meeres: „In meinem Gedächtnis sind auch Zungen / Meine Coolitude ist nicht ein Stein / Sie ist Koralle."7 Coolitude ist kein toter GedenkStein, sondern lebendig züngelnde, sprechende Koralle - allein: Wird hier die Sprache nicht zu obskur, zu ,schwierig‘?

Khal Torabully wusste sich hinsichtlich dieser Frage jedoch in bester literarischer, insbesondere karibischer Tradition. Hatte nicht José Lezama Lima im berühmten, von uns ausführlich kommentierten Auftaktsatz zu La expresión americana betont, dass allein das Schwierige stimuliert? Und hatte nicht Edouard Glissant aus der Karibik ebenfalls eine Ästhetik des Obskuren herausgearbeitet, in welcher nur das schwer Zugängliche die Komplexität poetischer Verdichtung wiederzugeben vermag? Torabully wusste sich dieser karibischen Tradition verpflichtet, war doch sein Gesprächspartner kein Geringerer als der martinikanische Dichter und Politiker Aimé Césaire gewesen, der als Poet der „Négritude“ auch fraglos einer der Stichwortgeber für das Konzept der „Coolitude“ gewesen war.

Nehmen wir diesen Stimulus also auf und denken ihn mit dem Dichter aus Mauritius weiter! Die für Torabullys eigenes Schreiben so wichtige Sprachenvielfalt und das Übersetzen wie das Übersetzen an andere Ufer stellen unablässige Transferprozesse dar, die immer wieder zu Transformationsvorgängen werden: „nicht mehr der Hindu-Mensch aus Kalkutta / sondern Korallenfleisch von den Antillen. "8 Hier verbindet sich die transarchipelische Dimension des Denkens

5 Torabully, Khal: Chair Corail, Fragments Coolies. Guadeloupe: Ibis Rouge Editions 1999.

6 Vgl. hierzu Deleuze, Gilles / Guattari, Félix: Rhizom. Aus dem Französischen übersetzt von Dagmar Berger u. a. Berlin: Merve Verlag 1977.

7 Torabully, Khal: Chair Corail, Fragments Coolies, S. 82: „Dans ma mémoire sont des langues aussi / Ma coolitude n'est pas une pierre non plus, / elle est corail.“

8 Ebda., S. 108: „non plus l'homme hindou de Calcutta / mais chair corail des Antilles.“ 
mit einer Transarealität, welche Grundlage für die Weiterentwicklung der Torabully'schen Ästhetik sein wird.

Aus diesen Mutationen, diesen Metamorphosen ergeben sich eine Schreibpraxis und zugleich eine Kulturtheorie, die beide unverkennbar transarchipelisch und transareal aufgebaut sind. So heißt es in Torabullys Beitrag für eine von der Universität Potsdam im Sommer 2011 veranstaltete Tagung programmatisch:

\begin{abstract}
Das die Coolitude begründende korallene Imaginäre stellt einen Vorschlag dar, um diese Verschiedenartigkeiten zu archipelisieren, die für die Menschheiten so notwendig sind (une proposition d'archipéliser ces diversités si nécessaires aux humanités). Es stellt ganz konkret unser Imaginäres aus den polylogischen, archipelischen Indien in die zeitgenössische Realität, wo Ökonomie, Kulturen und Ökologie nicht voneinander getrennt werden können, so wie dies die gegenwärtige Globalisierung mit ihren wiederholten Pannen voller Gewalttätigkeiten belegt. ${ }^{9}$
\end{abstract}

In diesen programmatischen Aussagen verbindet der Dichter aus Mauritius seine archipelische und transarchipelische Struktur einer weltweiten Relationalität mit einer zusätzlichen Dimension: er füllt sie schlicht mit Leben. Denn die inselhafte, geologische Struktur des Archipels wird durch eine lebendige Strukturierung verdoppelt, die in den Korallen eine Metaphorologie entfaltet, welche die gesamte Natur der Tropenwelt zusammenführt. Damit erweitert der Poet und Essayist der Coolitude seine Metaphorik um eine offene Struktur voller Leben und zugleich um die gesamte Fülle einer Natur, welche in all ihren tropischen und nicht-tropischen Dimensionen aufgezeigt wird. Denn Natur und Kultur bilden bei Torabully eine nicht auflösbare, nicht voneinander trennbare Einheit.

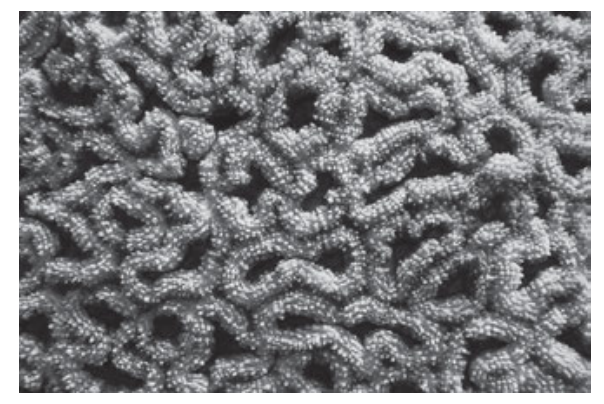

Abb. 129: Hirnkorallen-Struktur im Roten Meer bei Hurghada.

9 Torabully, Khal: Quand les Indes rencontrent les imaginaires du monde. In: Ette, Ottmar / Müller, Gesine (Hg.): Worldwide. Archipels de la mondialisation. Archipiélagos de la globalización. Madrid - Frankfurt am Main: Iberoamericana - Vervuert 2012, S. 63-72, hier S. 71. 
Er integriert damit eine grundlegend ökologische Vorstellungswelt, betont die wechselseitigen Verbindungen zwischen Natur und Kultur und ergänzt sein Schreiben dadurch um eine ökokritische Dimension zu einem Zeitpunkt, an dem das ökologische Überleben der Korallenwelt auf unserem Planeten in Gefahr ist. Und vor allem hinterfragt er eine Trennung zwischen Natur und Kultur, die schon im Bereich unserer Wissenschaftsorganisation mit der Aufspaltung zwischen den Naturwissenschaften und den Kulturwissenschaften, aber auch in unserem alltäglichen Denken und Handeln an der Tagesordnung ist.

Der französische Kulturanthropologe Philippe Descola hat sich intensiv mit dieser Problematik auseinandergesetzt und bereits im Jahr 2005 in seinem Buch Par-delà nature et culture grundlegende Einsichten in die Brüchigkeit und die Problematiken dieser auf den ersten Blick so natürlichen Trennung von Natur und Kultur untersucht und herausgearbeitet. Im Jahre 2011 erschien dann sein Band L'écologie des autres: l'anthropologie et la question de la nature in französischer Sprache, der 2014 ins Deutsche übersetzt wurde unter dem Titel Die Ökologie der Anderen: Die Anthropologie und die Frage der Natur. Hier versuchte Descola, im Kapitel „Schlussfolgerung“ einige seiner Leitideen zum Verhältnis von Natur und Kultur zusammenzufassen:

Man braucht kein Experte zu sein, um vorauszusagen, dass die Frage des Verhältnisses der Menschen zur Natur höchstwahrscheinlich die entscheidendste dieses Jahrhunderts sein wird. Man braucht sich nur umzusehen, um sich davon zu überzeugen: Die klimatischen Umwälzungen, der Rückgang der Artenvielfalt, die Vermehrung gentechnisch veränderter Organismen, das Versiegen der fossilen Energieträger, die Verschmutzung der empfindlichen Naturräume und der Megastädte, das sich beschleunigende Verschwinden der Tropenwälder, dies alles ist auf dem ganzen Planeten ein Thema öffentlicher Debatten geworden und schürt täglich die Ängste seiner Bewohner. Gleichzeitig ist es schwierig geworden, weiterhin zu glauben, dass die Natur ein vom sozialen Leben völlig getrennter Bereich ist, je nach den Umständen hypostasiert als Nährmutter, als nachtragende Rabenmutter oder als zu entschleiernde geheimnisvolle Schöne, ein Bereich, den die Menschen zu verstehen und zu kontrollieren suchten und dessen Launen sie zuweilen ausgesetzt seien, der jedoch ein Feld autonomer Regelmäßigkeiten bildet, in dem Werte, Konventionen und Ideologien keinen Platz hätten. ${ }^{10}$

Damit stellt der französische Anthropologe die Frage, die er für die Kernfrage des 21. Jahrhunderts hält: „Sag’, wie sieht das Verhältnis des Menschen zur Natur künftig aus?“ Die Antworten, die Descola auf diese Frage gibt, lassen es als unvermeidlich erscheinen, die Trennung zwischen Natur und Kultur in grundlegender

10 Descola, Philippe: Die Ökologie der Anderen: Die Anthropologie und die Frage der Natur. Berlin: Matthes \& Seitz 2014, S. 87. 


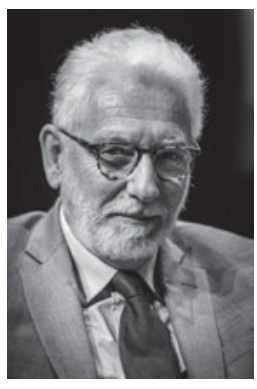

Abb. 130: Philippe Descola (Paris, 1949).

Weise in Frage zu stellen. Denn all das, was im Zeichen der Klimaveränderungen und aller anderen scheinbar auf die Natur zurückgehenden Transformationen uns als Menschen beängstigt und bedroht, sind Phänomene, bei denen der Mensch eine grundlegende Rolle gespielt hat, spielt und spielen wird. Mit anderen Worten: Der Mensch bedroht zum einen die Natur, indem er zur Verarmung des Planeten an geoökologischer Diversität beiträgt, ganze Spezies ausrottet und ein natürliches Gleichgewicht der Kräfte unterläuft. Zum anderen bedroht er die Kulturen des Planeten, insofern er die Konflikte zwischen verschiedenen Kulturen nicht beilegen kann und will, die Formen friedlicher Konvivenz in Differenz nicht entwickelt hat und zusätzlich durch seine Nukleartechnik das Überleben aller lebendigen Bewohner des Planeten insgesamt in Frage stellt.

Die Anthropologie ist dabei im Sinne Philippe Descolas jener Bereich, in dem sich Natur und Kultur auf grundlegende Weise überlappen und überschneiden: Sie bildet ein transdisziplinäres Feld, wo eine Trennung zwischen beiden Bereichen schlicht keinen Sinn mehr macht. Dies sind selbstverständlich Themen und Fragen, welche die Literaturen der Welt seit langer Zeit in grundlegender Weise stellen. Und es ist die Literatur, die sich auf sehr fundamentale Weise ökologisch verhält, indem sie in einen direkten Zusammenhang mit der Nachhaltigkeit gebracht werden kann. Denn nicht nur auf Grund ihrer intertextuellen Verfasstheit bildet die Literatur ein nachhaltiges und offenes System.

Doch wieder zurück zu Khal Torabully und einem Schreiben, welches sich dieser Entwicklungen höchst bewusst ist! Die Verbindung zwischen seiner engagierten Fürsprache für die Coolies, die sich ebenso über den Pazifik wie über die atlantische Welt verstreuten, und für die Korallen, die ersteren gleichsam das Überspülte, Überflutete repräsentieren, versuchte er in seinem Potsdamer Vortrag von 2011 wie folgt zusammenzufassen:

Die Koralle ist in ihrem lebendigen Habitat beobachtbar, ganz im Gegensatz zum Rhizom, das sich unter der Erde befindet. Darüber hinaus erlaubt sie mir, ein agglutinierendes Verbunden-Sein, das sich ähnlich wie ein Palimpsest aus Schichtung, aus Verdichtung, aus Sedimentierung aufbaut, und nicht nur ein erratisches Verbunden-Sein zu entwickeln, 
wobei sie den egalitären Aspekt der Verbindung beibehält, steht sie doch allen Strömungen gegenüber offen. Die Koralle ist ihrem Wesen selbst nach hybrid, denn sie ist aus der Symbiose eines Phytoplanktons und eines Zooplanktons geboren. In Sachen Metaphorik der Diversität könnte es schlicht nicht besser sein. Sie ist Wurzel, Polyp und Abplattung, ist von sich verändernder Form, schmiegsam und hart und dazu noch verschiedenfarbig. Obgleich sie verwurzelt ist, setzt sie doch die größte Migration auf der Erde frei, die des Plankton, die man vom Mond aus ebenso sehen kann wie das Great Barrier Reef, das von der UNESCO als Welterbe der Menschheit eingestuft wurde. Dieser korallene Archipel ist ganz einfach die auf der Erde sich am weitesten ausbreitende lebendige Skulptur, und auch sie kann man vom Mond aus sehen. ${ }^{11}$

Die Rekurrenz des Lexems „vivant“ beziehungsweise „lebendig“ am Anfang wie am Ende dieser Passage unterstreicht, in welch starkem Maße auch im Theorem der Koralle für Torabully Lebensprozesse von entscheidender Bedeutung sind. Es geht dem Schriftsteller aus Mauritius um eine fraktal verdichtete Form, in welcher alle Elemente und Daseinsformen der Natur mit Leben erfüllt sind und das Meer als Teil des Lebensraumes in eine poetische Gesamtsicht integriert ist. Die Koralle wird damit nicht nur zu einem Lebens-Theorem, sondern verkörpert in ihrer Lebendigkeit zugleich ein Wissen vom Überleben und $\mathrm{Zu}$ sammenleben, das diese Gemeinschaft von Lebewesen in ihrer sym-bio-tischen Daseinsform zu Kunstwerken von gewaltigen Ausmaßen anwachsen lässt. Der Begriff der Symbiose steht dabei im Bereich der Natur für ein Zusammenleben, welches im politischen und kulturellen Bereich als Konvivenz zu deuten wäre.

Dass sich die Koralle als Konkurrenzbegriff zur poststrukturalistischen Theorie des Rhizoms versteht, ist offenkundig; zugleich aber wird deutlich, dass Koralle und Rhizom durchaus in einer vergleichbaren Weise für das NichtZentrierte, für das Sich-Vernetzende und für das Nicht-Hierarchische einstehen. Dabei führt die Koralle in ihrem Oszillieren zwischen dem Fleisch - der „Chair Corail“ - und ihrer bildhauerischen Dimension als Gedenk-Stein eine dynamische Verbindung zwischen Geologie und Biologie, Tod und Leben, Gesellschaft und Gemeinschaft vor Augen, deren poetische Valenz in Torabullys Lyrik ausgespielt werden kann. Die symbiotische Welt der Koralle verbindet sich mit einer Konvivenz, die aus Perspektive der Tropen eine Lebens-Welt entstehen lässt, die sich unterhalb wie oberhalb der Meeresoberfläche ansiedelt. Als poetische Trope verkörpert die Koralle die Bewegungswelt der Tropen und versteht sich zugleich als Metapher für eine Welt, in welcher das Überflutete, das „sumergido“, nicht länger von der Erdoberfläche verschwunden ist, sondern seine Gegenwart

11 Torabully, Khal: Quand les Indes rencontrent les imaginaires du monde, S. 70 f. 
mit allen Sinnen manifestiert. Die Coolitude versteht sich so als integrative Kraft in einer Welt, in welcher alle Stimmen zählen und keine ungehört verhallen darf.

Es ist faszinierend $\mathrm{zu}$ sehen, wie mobil und bewegungsgeschichtlich der mauritianische Autor seinen Entwurf der Koralle anlegt, die man in einem allgemeinen Sinne gerade mit Blick auf die Grande Barrière eher mit Starrheit und Widerständigkeit assoziieren würde. Diese Beweglichkeit schließt ökologisch auch die Verwundbarkeit mit ein. Doch Khal Torabully hört auf das korallene Rauschen ihrer Geschichte, ihres Geschichtet-Seins, ihrer lebendigen Sedimentation. Erst aus dieser lebendigen Geschichte kleinster Lebewesen erwächst jene Widerständigkeit des riesigen Korallenriffs. Aber zugleich auch seine Zerstörbarkeit, wie sie durch die anthropogen verursachten Klimaveränderungen augenfällig wird.

Die von Torabully wiederholt betonte Verbindung zwischen Koralle und Migration ist innerhalb der Bild-Welten dieses Dichters und Theoretikers mit einer Coolitude verknüpft, die sich ebenso in das Ozeanische wie das Migratorische einschreibt. So heißt es in einem Vortrag des Kulturtheoretikers vor der UNESCO: „Es ist unmöglich, die Essenz der Coolitude ohne die Reise der Coolies über die Meere zu verstehen. Diese entscheidende Erfahrung, diese Odyssee der Coolies, hinterließ eine unauslöschliche Markierung in der imaginären Landschaft der Coolitude." $" 12$

Die hier implizit angesprochene Landschaft der Theorie bereichert zweifellos eine transareal über vier Phasen beschleunigter Globalisierung entfaltete Relationalität von in sich abgeschlossener Insel-Welt und archipelischer wie transarchipelischer Inselwelt insofern, als Coolie und Koralle nicht allein auf der Ebene einer sich verdichtenden Metaphorologie eine lebendige und weiter verlebendigende Dynamik in diese Insel-Landschaften der Theorie einbringen. Seine Begriffswelt ist zutiefst transareal geprägt und entfaltet eine Relationalität, die alle Bereiche unseres Planeten miteinander in Beziehung setzt und diese Beziehungen mit Leben füllt.

Es handelt sich um eine transareal konzipierte Landschaft der Theorie, die ohne die politischen, sozialen und kulturellen Kontexte der 1968 politisch unabhängig gewordenen Insel Mauritius sicherlich nicht hätte entworfen werden können. Schon die gleichsam zusammen mit der mauritianischen Geschichte

12 Torabully, Khal: The Coolies' Odyssey. In: The Unesco Courier (Paris) (October 1996), S. 13: „It is impossible to understand the essence of coolitude without charting the coolies' voyage across the seas. That decisive experience, that coolie odyssey, left an indelible stamp on the imaginary landscape of coolitude.“ 
und Gegenwart ,eingesogene‘ Vielsprachigkeit des Theoretikers und Dichters verschaffte diesem eine Ausgangsbasis, in welcher sich das Translinguale mit dem Transarchipelischen verbinden konnte. Denn die vor ihrer Kolonisierung unbewohnte Insel im Indischen Ozean, die unter der kolonialen Herrschaft Portugals (1505 - 1598), der Niederlande (1598 - 1710), Frankreichs (1715 - 1810) und Englands (1810 - 1968) stand, bündelt wie in einem Brennspiegel viele jener historischen Entwicklungen, die charakteristisch sind für eine ebenso transarchipelische und transareale wie translinguale und transkulturelle Vielverbundenheit. Dass sich Khal Torabully angesichts dieser Multirelationalität dann auch dem Konzept des Polylogischen öffnete, haben wir bereits gesehen.

Ganz so, wie sich auf religiöser Ebene Hinduismus, Katholizismus, Protestantismus und Islam auf engstem Raum begegnen, so lassen sich auf sprachliche Ebene neben dem „Morisyen“ (einer auf dem Französischen basierenden Kreolsprache, die nahezu von der gesamten Bevölkerung verwendet wird) auch verschiedene nordindische Varianten des Hindi, südindische Sprachen wie das Tamil sowie verschiedene südchinesische Dialekte unterscheiden. Dabei ist das Englische Amtssprache und das Französische wird nicht nur von einer Oberschicht als Muttersprache gesprochen, sondern herrscht in den Massenmedien vor. Ein sprachlicher, religiöser, kultureller Mikrokosmos, den Khal Torabully auf den Makrokosmos hin zu öffnen suchte.

Auch wenn der vielsprachige Autor in seinen Schriften wie in seinem Schreiben gewiss nicht alle sprachlichen wie translingualen Dimensionen auszuleuchten vermag, so kann doch kein Zweifel daran bestehen, wie sehr seine theoretische Prosa und seine lyrische Praxis von ständigen sprachenquerenden Prozessen geprägt sind. Dies bedeutet freilich nicht, dass sich der Kulturtheoretiker nicht immer wieder sehr pragmatisch der Erforschung und Präsentation kultureller Querverbindungen gewidmet hätte. So organisierte er beispielsweise auf der französischen Karibikinsel Guadeloupe im Mai 2018 das Festival International de la Coolitude, das die zuvor über lange Jahrzehnte kulturell marginalisierte indische Community in der Fülle ihrer transatlantischen wie transpazifischen Beziehungen leuchten ließ und einen Gegenpol zur französischen Kulturpolitik auf der Insel darstellte. Immer wieder erweist sich der mauritianische Dichter somit als eine Figur, welche weltumspannende transkulturelle Beziehungen gerade zwischen den Inseln mit Leben erfüllt.

Für Khal Torabully selbst, der nicht nur in Frankreich oder auf Mauritius, in der Karibik oder in Andalusien anzutreffen ist, steht die menschliche Existenz im Zeichen eines Exils, wie es eindrücklich auch am Ende von Erich Auerbachs Aufsatz Philologie der Weltliteratur für seine Konzeption der Romanistik steht. Letztere begreift sich bei dem nach seinem Istanbuler Exil nicht mehr dauerhaft nach Deutschland zurückgekehrten Literaturwissenschaftler als eine Philologie 
ohne festen Wohnsitz. ${ }^{13}$ Dementsprechend entfaltet der mauritianische Dichter in einem Gedicht aus dem im Jahr 2012 erschienenen und als Roman bezeichneten Band L'arabesque andalouse ou L'œuf et la colombe rund um die Sierra Nevada und die arabische Welt Granadas eine Landschaft der Theorie, welche deutlich im Zeichen von Schmerz und Exil steht:

Jetzt, im rosafarbenen Schnee des Morgens in der Sierra Nevada, drehe ich mich noch einmal mit weniger schwerem Herzen um in der Hoffnung, dass dieser Ring in der Hand eines anderen Weisen sein könnte, und dass der neue Tag niemanden vor der Türe ließe, ohne ihm zumindest ein Fragment seines Aufscheinens zu schenken.

Der Schnee erstrahlt in Tönungen einer rötlichen Sonne. Rosafarben strahlend.

Und in diesem einzigartigen Lichte Andalusiens, in welchem jeder Blinde sehen kann, indem er die Zukunft der Welt imaginiert, empfand ich den grässlichsten Schmerz meines Lebens.

Es ist das verletzte Licht, das auf die Dinge blutet, die wir so sehr geliebt.

Ist dies die schreckliche Luzidität der Exilierten? ${ }^{14}$

Im Schnee der Höhen der Sierra Nevada, die im Süden Spaniens schon so manchen schneeblind werden ließen, erscheint eine Welt, in welcher im Zeichen der Alhambra Christentum und Islam, Spanier und Araber niemals lange friedlich zusammenzuleben verstanden. Sie haben sich vielmehr dem Kampfe und dem Konflikt geweiht, unfähig, auf einem Planeten der verschiedensten Kulturen, Ethnien und Religionen eine Konvivenz zu finden, die doch so notwendig für die Menschheit wäre. So wie die Ökologie der Koralle stets vom Menschen bedroht ist, so zeigt sich auch eine Welt, die im gleißenden Licht der Gipfel erstrahlt, doch immer einer Gefahr ausgesetzt, welche alles Leben bedroht. Der Mensch kann dies vielleicht nur aus der grundlegenden Sicht seines eigenen Exils heraus verstehen - oder aus dem Blickwinkel eines ZwischenWeltenSchreibens, dem wir den nach eigenem Geständnis auf Kreolisch denkenden, aber auf Englisch und Französisch schreibenden Khal Torabully zweifellos zuordnen können.

Doch das Schreiben des Schriftstellers aus Mauritius begehrt nicht gegen die Luzidität, wohl aber die Exilierung des Menschen auf. An die Stelle einer Kette ständiger Kämpfe und wechselseitiger Exklusionen - „Der Weiße weist den

13 Vgl. hierzu Ette, Ottmar: Toward a Polylogical Philology of the Literatures of the World. In: Modern Language Quarterly (Seattle) LXXVII, 2 (June 2016), S. 143-173.

14 Torabully, Khal: L'arabesque andalouse ou L'œuf ou la colombe. Port-Louis: Editions K’A 2012, S. 73. 
Schwarzen zurück und dieser den Coolie“15 - setzt der Autor von Chair Corail, Fragments Coolies ein Schreiben, das sich im Verbund mit Schreibformen weiß, die (in einer oftmals diasporischen Situation) vielsprachige ,imaginaires polylogiques et archipéliques“, die Kräfte und Chancen des Viellogischen entfesseln. Sie öffnen sich auf eine „Kontaminierung von Diskursen, Gattungen, Orten und sogar Sprachen“, ${ }^{16}$ die keinerlei raumgeschichtlicher, territorialisierender Rückbindung mehr unterliegt. Indien wird auf diese Weise neu pluralisiert, erfährt als „les Indes“, „las Indias“ oder „the Indies“ nun eine selbstgesteuerte Orientierung, in der Ost-Indien und West-Indien, Asien und Australien, Europa, Amerika und Ozeanien auf literarischer wie kulturtheoretischer Ebene in eine wechselseitige Vielgestaltigkeit von Relationen einbezogen werden. Darauf ruht die Hoffnung eines literarischen Euvres, das sich der Gefahren und Risiken bewusst ist, mit welchen der Mensch ebenso die Natur wie die Kultur unseres Planeten bedroht. Das Überleben der Korallen ist mit dem der Menschheit auf viele Weisen verknüpft. Die vielsprachigen Literaturen der Welt versuchen, sich all diesen Gefahren mit bisweilen schmerzhafter Luzidität, ästhetischer Differenziertheit und polylogischer Komplexität entgegenzustellen.

Vor diesem Hintergrund möchte ich mich in der Folge mit einem Roman beschäftigen, der für den Kontext unserer Vorlesung in mehrfacher Hinsicht interessant ist. Es handelt sich um einen relativ kurzen, wenig umfangreichen, im Jahr 2000 erschienenen Romanerstling aus der Feder der haitianischen Autorin Yanick Lahens mit dem Titel Dans la maison du père, der auch in deutscher Übersetzung erschienen ist. Dieser erste Roman der in Port-au-Prince lebenden Literaturkritikerin, Literaturwissenschaftlerin und Erzählerin wurde 2002 mit einem Förderpreis der Leipziger Buchmesse ausgezeichnet; aber hierin liegt nicht das für uns Aufschlussreiche hinsichtlich der fließenden Übergänge zwischen postmodernem und nachpostmodernem Schreiben.

Bei der Analyse dieses Romans kommt Bewegungen unterschiedlichster Art eine entscheidende Bedeutung zu. Dazu zählen zunächst und vor allem die Bewegungen des Körpers, die den Text von Beginn an beherrschen. Denn die Protagonistin dieses Romans, der in vielfacher Hinsicht ein Rückblick auf das 20. Jahrhundert aus der Perspektive eines Lebens ist, wird in ihrer schwierigen persönlichen Bildungsgeschichte zu einer Tänzerin. Diese Entwicklung zeichnet sich bereits in frühester Jugend ab, als wir sie im Hause ihres Vaters - daher auch der Titel des Romans - zum ersten Mal tanzen und ihren Körper in Bewegung

15 Torabully, Khal: Quand les Indes rencontrent les imaginaires du monde, S. 69: „le blanc rejetant le noir qui rejette le coolie.“

16 Ebda., S. 70: „contamination de discours, genres, lieux et même de langues.“ 
sehen. Das Verhältnis von Leib-Sein und Körper-Haben, ${ }^{17}$ von Subjektivität und Objekthaftigkeit des weiblichen Körper-Leibes, ist von Beginn an eines der zentralen Themen eines Bandes, in welchem der Genderfrage eine große Bedeutung zukommt.

Zum zweiten betreffen diese Bewegungen aber auch das Exil und die verschiedenen Fluchtbewegungen, die fast das gesamte Personal des Romans erfassen und in den abschließenden Kapiteln geradezu lakonisch erzählt werden. Es sind Lebensgeschichten von Haitianern und Haitianerinnen, die es in die USA oder nach Europa, ins Zentrum Manhattans oder ins eisige Finnland, nach Kuba oder Frankreich verschlägt. Haiti erscheint als Insel im Archipel der Welt, deren Bewegungen zentrifugal aufgebaut sind und die mit den Geschichten ihrer Fluchtbewegungen vorrangig ihre eigene Geschichte schreibt. All diese Lebensgeschichten und Schicksale der von der Teil-Insel Aufgebrochenen eint die Erfahrung, dass Haiti wohl noch keine einzige Phase der Geschichte erfahren hat, die man als glücklich bezeichnen könnte. Und alle Figuren verbindet die Einsicht, dass Haiti kein Land zu sein scheint, in dem man ganz einfach leben könnte. Diese Erkenntnis, dieses Lebenswissen wird - wie wir noch sehen werden - gegen Ende des Romans mehrfach thematisiert und behandelt. Das Eigene bietet keinen Platz zum Leben: Die Fremde muss zum Eigenen werden.

Die 1953 in Port-au-Prince geborene Autorin Yanick Lahens freilich ist auf Haiti aufgewachsen, studierte an der Sorbonne in Paris, aber kehrte wieder nach Haiti zurück; sie ist dort, all ihrer Reisen zum Trotz, geblieben, wo sie mit viel Glück das Erdbeben von 2010 überlebte - eine Erfahrung, die sie in einem Buch verarbeitete. ${ }^{18}$ Sie ist in Haiti an der Ecole Normale supérieure der Universität von Port-au-Prince tätig, so dass sie gleichzeitig als Literatin und als Literaturwissenschaftlerin angesprochen werden kann, die 1990 erstmals mit ihrem auch ins Englische übersetzten Essay L'exil entre l'ancrage et la fuite erstmals auf sich aufmerksam gemacht hat.

Doch die Poeta docta ist in ihrer Heimat vor allem auch als Moderatorin von Radio- und Fernsehprogrammen bekannt, wobei sie ihre mediale Kompetenz immer wieder in den Dienst gesellschaftlich engagierter Projekte stellte. Ich

17 Vgl. hierzu Ette, Ottmar: Hand-Schrift und Körper-Leib. Alteritätserfahrung, autobiographisches Schreiben und Leibhaftigkeit in einem frühen Gedicht Hannah Arendts. In: Leinen, Frank (Hg.): Literarische Begegnungen. Romanische Studien zur kulturellen Identität, Differenz und Alterität. Festschrift für Karl Hölz zum 60. Geburtstag. Berlin: Erich Schmidt Verlag 2002, S. 153-187. 18 Lahens, Yanick: Failles. Und plötzlich tut sich der Boden auf. Ein Journal. Zürich: Rotpunktverlag 2011. 


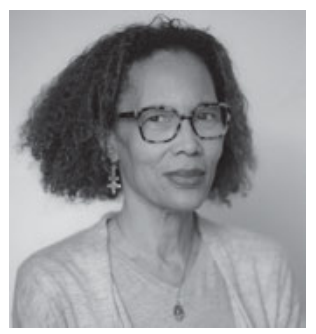

Abb. 131: Yanick Lahens (Port-au-Prince, Haiti, 1953).

konnte mit der haitianischen Autorin im Jahr 2002 ein Interview führen, ${ }^{19}$ in dem sich die Autorin als geborene „in-between“, als einen Menschen beschreibt, der sozusagen dazwischensteht oder - anders gesagt - die Zwischenräume bewohnt und sie für seine Kreativität nutzt und benutzt. Wir können die sich auf Kreolisch und Französisch ausdrückende Yanick Lahens in diesem Sinne als eine Schriftstellerin des ZwischenWeltenSchreibens bezeichnen, auch wenn sie ihr „pays natal" niemals dauerhaft verlassen und ein Exil sie bislang noch nicht von ihrer Heimatinsel vertrieben hat.

Immer wieder beschäftigte sich die studierte Komparatistin mit der spezifischen Situation der haitianischen Literatur, für deren nationale wie internationale Förderung sie sich einsetzt. Als Gründungsmitglied der haitianischen Schriftstellervereinigung zählt sie heute zu den profiliertesten Intellektuellen ihres Landes. Nach dem Ende der Duvalier-Diktatur sieht sie die offene Wunde Haitis gerade auch in jener verlorenen Generation, die durch Unterdrückung, Flucht und Exil in einem dauerhaften Prekariat lebte und sich nur mit größten Schwierigkeiten auszudrücken verstand. Immer wieder betonte die Literaturwissenschaftlerin dabei, dass ihr Haiti wie ein immenses Labor vorkomme, in welchem weltumspannende Situationen der Zukunft - insbesondere Migration und Transmigration, Exil und das Schreiben jenseits der Muttersprache - schon einmal erprobt und ausgetestet würden.

Die bis heute fortdauernde Situation der Republik Haiti bringt es mit sich, dass sich viele Autorinnen und Autoren außerhalb ihres Landes befinden und vor allem in Kanada und Frankreich Zuflucht gesucht haben. Ohne an dieser Stelle auf die überaus spannende und kontroverse Geschichte der haitianischen Literatur eingehen zu können, erscheint bei allen grundlegenden Unterschieden diese Literatur doch als vergleichbar mit anderen Literaturen im karibischen Raum. Denn wie die kubanische ist auch die haitianische Literatur seit dem 19. Jahr-

19 Vgl. Ette, Ottmar: „Faire éclater la problématique d'une littérature nationale“. Entretien avec la romancière haïtienne Yanick Lahens à Berlin, le 24 mars 2002. In: Lendemains (Tübingen) XXVII, 105-106 (2002), S. 221-235. 
hundert von der Erfahrung des Exils gezeichnet und lässt sich als Literatur ohne festen Wohnsitz verstehen. ${ }^{20}$ Innerhalb der Literaturen der Welt nimmt letztere im Bereich der Frankophonie auf Grund ihrer Stärke und Widerständigkeit, ihrer ästhetischen Kraft und Dynamik zweifellos eine Sonderstellung ein.

Doch beschäftigen wir uns nun mit dem Debütroman der Haitianerin, der sich - wie bereits erwähnt - als Rückschau auf das 20. Jahrhundert aus der Perspektive des Jahres 2000 begreifen lässt! Der zentrale Handlungsstrang dreht sich um die Geschichte einer Familie aus einer Position, welche sich sehr wohl als „intimiste“ bezeichnen ließe. Denn es geht um eine Entdeckungsreise durch den Bereich des Körperlichen und Sinnlichen, die über weite Strecken des Romans, die historisch in den vierziger Jahren angesiedelt sind, erprobt wird. Im Kern haben wir es mit der Entdeckung des eigenen weiblichen Körpers zu tun und zugleich mit der Entdeckung einer Kultur, die aus dem Hause des eigenen Vaters ausgesperrt ist. Doch im Hinterhof dieses Hauses hält das Dienstmädchen Man Bo diese verleugnete, ausgegrenzte, marginalisierte Kultur lebendig und gegenwärtig.

Der Roman ist mit einer homo- und zugleich intradiegetischen weiblichen Erzählerfigur ausgestattet, die ihre eigene Geschichte in der ersten Person Singular erzählt und dabei vor allem von ihren Erlebnissen und Erfahrungen als Kind und Jugendliche im Haus des Vaters bis zu ihrem Entschluss berichtet, Tänzerin zu werden und das Land in Richtung USA zu verlassen. Spät erst wird sie wieder nach Haiti zurückkehren und nach dem Tod ihrer Eltern schließlich jenes Haus des Vaters bewohnen, dessen geöffnete Türen und Fenster den Romananfang prägen.

Vielfältige intertextuelle Beziehungen $\mathrm{zu}$ anderen Autor^innen und Texten, insbesondere zu Dany Laferrière, dem Verfasser des Debütromans Comment faire l'amour avec un nègre sans se fatiguer, ließen sich herstellen. Sein im selben Jahr 2000 erschienener Roman Le Cri des oiseaux fous wäre ebenfalls ein ausgezeichnetes Beispiel für diese Literaturen ohne festen Wohnsitz, die einen wesentlichen Bestandteil der aktuellen Literaturszene weltweit darstellen. Als abschließender Roman seiner sogenannten ,amerikanischen Autobiographie“ berichtet er von den letzten vierundzwanzig Stunden eines Mannes vor dessen Ausreise aus Haiti, der von seiner drohenden Ermordung durch die Duvalier'sche Schlägertruppe der „Tontons Macoutes“ erfahren hat. Der Text besitzt einen ebenso familiengeschichtlichen wie autobiographischen Hintergrund. Doch bleiben wir bei dem Roman von Yanick Lahens!

20 Vgl. hierzu Ette, Ottmar: Eine Literatur ohne festen Wohnsitz. Fiktionen und Friktionen der kubanischen Literatur im 20. Jahrhundert. In: Romanistische Zeitschrift für Literaturgeschichte / Cahiers d'Histoire des Littératures Romanes (Heidelberg) XXVIII, 3-4 (2004), S. 457-481. 
Bewegungen stehen im Zentrum von Dans la maison du père. Das Tanzen wird für die Protagonistin zur einzigen Chance, ihre lebensgeschichtliche Entwicklung gleichsam zur Freiheit zu führen. Es ist das Wissen und Können, ihren Körper zu bewegen, welche letztlich als Ausdrucksformen weiblichen Lebenswissens auch die Möglichkeiten eröffnen, sich über die Grenzen des Landes hinaus zu bewegen und sich einen Raum der Freiheit zu schaffen, der im Haiti der vierziger Jahre undenkbar ist. So wird unsere Protagonistin Alice Bienaimé in ihrem eigenen Land keineswegs wohlgelitten, und - um der ironischen literarischen Anspielung $\mathrm{zu}$ folgen - dort auch nicht zu Alice in Wonderland.

Ihr Weg zur Selbstbestimmung als Frau in einer durch und durch patriarchalischen Gesellschaft, welche sich schon im Titel des Romans ankündigt, erweist sich als überaus steinig und schwierig. Er führt weniger über die Mutter, deren Schatten sie - wie es in einer Passage des Romans heißt - noch immer liebe, weil es der Schatten jener Frau sei, die ihre Mutter nicht hatte sein können, sondern erstaunlicherweise eher über den Vater. Es ist durchaus bemerkenswert, dass damit weniger die Dimension der Muttersprache als jene des Vaterlandes thematisiert wird, denn das Mädchen will ja nicht Schriftstellerin, sondern Tänzerin werden. Es geht folglich weniger um die „langue maternelle“ in einem Roman, in dem sich alles um Körperkünste, um Tanzen und damit nonverbale Ausdrucksformen dreht, als um die Frage der „patrie“, des Territoriums und - wie dies bereits im Titel erscheint - um das Haus ihres Vaters.

Wir sehen der Protagonistin in ihrem Bildungsroman dabei zu, wie sie dank der Komplizenschaft ihres Onkels Héraclès - ein weiterer, wahrhaft sprechender Name, der nicht weniger ironisch verwendet wird - die Sprache ihres Körpers zu verstehen und zu sprechen lernt, bis sie in Manhattan eine berühmte Tänzerin wird. Erst in fortgeschrittenem Alter, als sie ihre Glieder nicht mehr so gut wie früher bewegt, kehrt sie nach Haiti zurück und verbringt ihr Lebensende im Haus ihres Vaters, das natürlich von jenen Erinnerungen bewohnt wird, welche in die vierziger Jahre zurückreichen. Alice Bienaimé ist es gelungen, diese kleinbürgerliche Welt des Vaters zu verlassen, der ihr in einem späten Brief noch bescheinigte, dass sie das einzig Richtige getan habe. Die späte Einsicht der Vaterfigur mag belegen, dass die Flucht aus der Familie nicht als völliger Bruch, sondern als Form der - gewiss räumlich getrennten - Konvivenz gewählt wird.

So wird es auch niemals zu einem Bruch mit dem Vater im eigentlichen Sinne kommen, obwohl dieser die Ich-Erzählerin am Anfang des Romans ohrfeigt. Die eigenständige Tochter aber wird sich nicht im Zorn von ihm trennen: Sie wird die Beziehungen zur Familie trotz der räumlichen Distanz nicht aufkündigen, eine Tatsache, die wir bei der Deutung unseres Romans auf Ebene der Allegorese durchaus mitberücksichtigen müssen. Dergestalt können wir die Nabelschnur, von der in Aimé Césaires dem Roman vorangestellten Motto die Rede ist, als jenes 
verbindende Element begreifen, das auch im Exil immer noch eine Herkunft auszeichnet, von der sich die Ich-Erzählerin ebenso wenig distanziert wie die reale Autorin Yanick Lahens von Haiti.

Als Arzt hätte der Vater seiner Tochter gute Startbedingungen ins eigene Leben verschaffen können. Doch die Tochter lehnt dies ab. In den Rückblick der alt gewordenen Tänzerin auf ihr eigenes Leben, in diese Fiktion einer Autobiographie, mischen sich vielfältige historische Daten und Reminiszenzen, die von den US-amerikanischen Interventionen und dem Massaker von 1937 an haitianischen Bauern in der Dominikanischen Republik bis hin zur sogenannten „Campagne anti-superstitieuse“, der Revolution von Januar 1946 oder den großen künstlerischen Entwicklungen der vierziger Jahre reichen. Auch Elemente einer karibischen Literaturgeschichte und einer Auseinandersetzung mit Vorstellungen avantgardistischer Autoren werden eingeblendet, insofern etwa die Besuche der beiden kubanischen Schriftsteller Nicolás Guillén und Alejo Carpentier auf Haiti Erwähnung finden. Das Land war zum damaligen Zeitpunkt eine wichtige Drehscheibe für Ziele und Projektionen der historischen Avantgarden ebenso in der Karibik und in Lateinamerika wie in Frankreich und anderen Teilen Europas. ${ }^{21}$ Beide kubanischen Autoren werden zu einem wichtigen Bestandteil des innerliterarischen Raumes, zu dem nicht zuletzt auch Aimé Césaire oder Jacques Roumain, folglich karibische Hauptvertreter der Négritude, als wesentliche intertextuelle Bezugspunkte gehören.

Stets ist die Vaterfigur in dieser Geschichte - wie auch in der Geschichte Haitis - von zentraler Bedeutung: Denn er ist es, der die Berührung mit schwarzen Kultur-Traditionen zu unterbinden versucht, der den Kontakt mit dem Voodoo verbietet, der wesentlich stärker als seine Frau, die schon mit dreißig Jahren resigniert hat, das Leben aller anderen Figuren zu bestimmen sucht. Allerdings verfällt mit der Zeit sein Bild, das in den Augen der Tochter ursprünglich das eines wunderbaren Helden war, zusehends und macht dem Portrait eines weitaus weniger positiv gezeichneten patriarchalischen Mannes Platz, der aus seinem eigenen Arrangement mit einer Welt, die von Unterdrückung, Elend und Abhängigkeit, aber auch von vielfältigsten Verboten geprägt ist, nicht mehr auszubrechen vermag.

Die Eingangsszene des Romans, die explizit den Schlüssel eines ganzen Lebens enthält, siedelt sich im Jahr 1943 an; zu einem Zeitpunkt, an dem die jugendliche

21 Vgl. hierzu Birkenmaier, Anke: Alejo Carpentier y el „Bureau d’Ethnologie Haïtienne“. Los cantos en „El reino de este mundo“. In: Collard, Patrick / De Maeseneer, Rita (Hg.): El Centenario de Carpentier (1904-2004). Madrid: Foro Hispánico 2004, S. 17-35; sowie dies.: Alejo Carpentier y la cultura del surrealismo en América Latina. Madrid - Frankfurt am Main: Iberoamericana Vervuert 2006. 
Protagonistin gerade dreizehn Jahre alt geworden ist. Da sie - so ließe sich die Chronologie rekonstruieren - in den Monaten vor August 1929 geboren sein muss und bisweilen mit Blick auf die vierziger Jahre von einem Zeitraum von fünfzig Jahren spricht, dürfen wir annehmen, dass sich die letzten Szenen ihrer Rückkehr nach Haiti in den neunziger Jahren abspielen. Es handelt sich dabei um eine Epoche, in welcher Alice Bienaimé über sechzig Jahre alt ist und auf ihr ganzes Leben zurückblicken kann. Den größten Teil dieses Lebens hat sie nicht auf Haiti, sondern im Exil verbracht, fernab ihrer heimatlichen Insel. Dies ist die Differenz zwischen Erzählzeit und erzählter Zeit, die den Roman in seiner Anlage auf der Zeitachse, aber auch in seinen narrativen Bewegungen, grundlegend strukturiert.

In der Folge möchte ich Ihnen zunächst das erste der insgesamt dreiunddreißig durchnummerierten Kapitel von Dans la maison du père vorstellen und einmal mehr mit dem Incipit beginnen, das uns - in leicht gekürzter Form - einen ersten Zugang zur Welt dieses Romans erlauben soll:

Das Haus liegt am Ende einer Hibiskus-Allee, alle Türen und alle Fenster stehen offen. Ragtime-Musik, die seit einiger Zeit in Mode ist, kommt aus dem Trichter eines Grammophons, das auf einem Säulentischchen in der Ecke des Salons steht. Schon ab den ersten Noten drehe ich mich in meinem blauen Kleid. Ich bewege lachend meine Beine. Klatsche in die Hände. Ich watschle von links nach rechts. Eine Frau steht aus ihrem Sessel auf, entrollt ihren Seidenschal, legt ihr leichtes Strickwestchen ab und kommt zu mir, inmitten der Möbel des Salons. Die Frau macht dieselben Bewegungen wie ich. Freilich etwas diskreter. Seit sie bei mir ist, lache ich noch lauter. Noch ein wenig mehr und meine Lungen werden platzen, mein Herz sich lösen und zu meinen Füßen fallen.

[...]

Einige Minuten später verlasse ich mit kleinen Sprüngen das Haus und wende mich dem Garten zu. In dem Maße, in dem sich die Grammophonmusik entfernt, pfeife ich leise die Ragtime-Melodie. Die Musik verfolgt mich noch eine Zeitlang. Ich laufe im Gras, drehe mich wieder um mich selbst, bewege meine Arme von hinten nach vorne, bis mich ein leichter Schwindel erfasst ... Und plötzlich ergreift mich so etwas wie eine dunkle und freudige Kraft und verändert meine Rhythmen. Ich ziehe meine Schuhe, meine weißen Söckchen aus und suche nach dem Takt einer anderen Musik, nach anderen Gesten, die von einer Trommel vorwärtsgetrieben werden, Klängen, die ich einige Wochen zuvor in einer entfernten Lichtung in Rivière Froide hörte, dort hinten in einer Vorstadt. Ich gehe in die Knie, mache meine Schultern rund, wiege meinen Rücken und schreite in kaum rhythmisierten kleinen Schritten vorwärts. Ich kauere mich nieder, bis ich den Boden berühre, und bewege mich weiter, ohne aufzuhören. Nach einem Augenblick bin nicht mehr ich es, die tanzt, der Tanz durchläuft mich und lässt mein Blut schlagen.

Der Mann im weißen Alpaka-Anzug lässt mich nicht aus den Augen. [...] Nur einige Meter von mir entfernt, rennt er plötzlich los, ergreift mich und fällt auf mich wie eine Fackel in ein Zuckerrohr-Feld. Er hält mich brutal an den Schultern fest, schreit mich an, ich solle sofort mit diesem ... vermaledeiten Tanz aufhören und verpasst mir eine Ohrfeige. ${ }^{22}$

22 Lahens, Yanick: Dans la maison du père. Paris: Le Serpent à plumes 2000, S. 11 f. 
In dieser sorgsam aufgebauten Eingangspassage von Dans la maison du père lernen wir zunächst das Haus des Vaters kennen, das wohlsituiert am Ende einer kleinen Allee auf den ersten Blick gegenüber den Außenräumen offen zu sein scheint. Die Ich-Erzählerin tanzt zu den Rhythmen eines Ragtime, der damals Mode war, womit zugleich auf den Zeitraum, die vierziger Jahre, verwiesen wird. Die zweite Frau tanzt diskreter und lacht nicht so sehr wie die Ich-Figur, die lustvoll bis an die Grenzen ihrer körperlichen Belastbarkeit geht. Wir werden später erfahren, dass diese zweite Frau die damals etwa dreißigjährige Mutter der Protagonistin war, die freilich niemals ihr eigenes Leben führen konnte, niemals aus dem Schatten ihrer eigenen Gestalt in der patriarchalischen Gesellschaft Haitis heraustreten konnte.

Die räumliche Situierung wird sehr präzise vorgenommen: Wir sind in Haiti, auf der Insel Hispaniola, in den karibischen Tropen, in einem gut bürgerlich eingerichteten Haus mit Grammophon, einem Salon und schönen Möbeln. Auch die gute Kleidung der Romanfiguren - wie etwa der Anzug, der Seidenschal oder das blaue Kleid der Erzählerin - verweist darauf, dass wir uns in einem gesellschaftlich wohlsituierten Ambiente bewegen, war doch allein schon die Anschaffung eines Grammophons in den vierziger Jahren nur einer Minderheit der haitianischen Bevölkerung möglich. Das Haus befindet sich in einem Viertel, das weit entfernt liegt von den Vorstädten der Hauptstadt Port-au-Prince. Die Szene könnte sich so oder so ähnlich in der Kindheit der haitianischen Autorin abgespielt haben, stammt sie doch aus einer gutbürgerlichen, in der Hauptstadt ansässigen Familie. Und es gibt ein Element, das auffällig ist. Denn Worte werden nicht gewechselt: Die Körper bewegen sich im Rhythmus einer Musik, die sozusagen importiert, aus der westlich-abendländischen Kulturzone ebenso eingeführt wird wie das Grammophon, mit Hilfe dessen sie erklingt. Das mediale Setting des ersten Teils der Eingangsszene ist daher überaus spannend.

Als Gegenraum zu diesem Innenraum wird in einem zweiten Schritt im Incipit der Garten des Hauses aufgebaut. Erst später im Roman werden wir erfahren, dass in diesem Bereich - wie insbesondere auch im Hinterhof des Hauses - das Dienstmädchen Man Bo die eigentliche Herrscherin ist und das Sagen hat. Der Außenraum des Gartens bildet einen Raum, in dem die Musik des Innenraums, des Salons, langsam, wie in einem Schwellenbereich, verklingt. Doch die Ich-Erzählerin und Tänzerin hat eine unsichtbare Schwelle bereits überschritten, von der sie in diesen Augenblicken noch nichts ahnt. Sie hat den kultivierten Bereich der mit ihr tanzenden Mutter schon verlassen und steht nunmehr unter Beobachtung des gut gekleideten Vaters.

Gegen die importierte westliche Ragtime-Musik, die noch körperlich auf den Lippen der Ich-Erzählerin eine Weile fortklingt, wird zunehmend eine andere Musik in Szene gesetzt, die gleichsam aus der Erinnerung an eine kurz zuvor 
erlebte Szenerie in den Randbereichen der Stadt Port-au-Prince entsteht. Sie besitzt eine obskure Kraft, denn sie wird nirgendwo abgespielt, sondern geht aus einer Erinnerungsleistung der Erzählerin hervor. Es sind ganz andere, der Protagonistin noch fremde Rhythmen: eine Trommelmusik, Gesten und Bewegungen, die in krassem Gegensatz zu den kontrollierten Rhythmen und Bewegungen des Ragtime stehen. Um diese Bewegungen ausführen zu können, muss sich die Erzählerin ihre Schuhe und ihre weißen Strümpfchen ausziehen: Sie tanzt nun nicht mehr im Innenraum auf einem schönen Fußboden, sondern im Außenraum des Gartens auf einem Boden, den sie mit ihren bloßen Füßen berührt. Hier nun entwickelt sie eine andere Körpersprache, die recht bald ekstatische Züge erhält, bemächtigt sich der Tanz doch unverkennbar der Protagonistin, die gleichsam nicht mehr tanzt, sondern von diesen ihr noch fremden Rhythmen getanzt wird und sich auf gänzlich andere Weise bewegt. In den Körper-Leib schreibt sich ein Fremdes ein, das doch ein Eigenes ist: der Vorderseite westlicher Musik stellt sich eine Rückseite gegenüber, die von Rhythmen erfüllt ist, welche von Afrika her transportiert und auf der Karibikinsel transformiert wurden. Ihr Körper wird von ihr weniger als Objekt bewegt, sondern vielmehr als Leib von Schwingungen und Rhythmen erfasst.

In diese präzise konstruierte Szenerie nun bricht die männliche Figur herein, die gemeinsam mit anderen die Szenerie von Beginn an beobachtet hat und gleichsam das erste Publikum jener künftigen Tänzerin bildet, zu der auch wir als Leserschaft gehören. Wir wohnen einer Geburtsszene bei: Eine haitianische Tänzerin wird geboren. Unterschiedliche Rhythmen queren ihren Körper-Leib, verwandeln ihn in eine Ausdrucksform transkultureller Bewegungen. Doch der Mann im weißen Alpaka-Anzug unterbricht nicht nur diesen zweiten Tanz, sondern wirft sich gewaltsam auf die Tanzende, unterdrückt sie, zwingt sie dazu, diesen vermaledeiten Tanz zu beenden, um sie dann schließlich zu ohrfeigen. Es ist eine Szene vollkommener Überraschung, einer Gewalt, die aus dem Nichts zu kommen scheint, und doch präzisen Frontlinien folgt. Denn die Ich-Erzählerin hat unbewusst eine unsichtbare Schwelle überschritten. Und dies wird mit Gewalt beantwortet, wird gewaltvoll unterdrückt.

Die zunächst aus der Distanz gezeichnete männliche Figur ist - wie wir wenige Absätze später erfahren - der Vater, der kraft seiner väterlichen Gewalt die andere Kultur, das Fremde, das ihm aber wohlbekannt ist, mit Macht zu unterdrücken sucht. Es ist eine Gewalt am Körper, welche das Fremde aus dem Körper der Tochter freilich nicht mehr herausbefördern kann. Denn die anderen Rhythmen haben das Leib-Sein der Tochter längst erfasst, sind zu einem Teil der Tochter geworden: unsinnig, sie noch herausprügeln zu wollen. Ihre transkulturelle Tanzkarriere hat begonnen ... 
Diese nicht aus Europa, dem vermeintlichen kulturellen Zentrum, stammende Gegenkultur ist die Kultur des Außenraums. Diese ist völlig marginalisiert, an den Rand gedrückt, aber gerade deshalb außerhalb des Hauses des Vaters nur schwer kontrollierbar. Sie enthält andere Versprechen, beruht auf einer Kultur, die nicht aus dem für die höheren Klassen Vorbild gebenden Westen importiert wird, sondern sich in Haiti entfaltet hat, auch wenn sie auf kulturelle Entwicklungen zurückgeht, welche die afrikanische Herkunft modellieren. So stehen sich hier unvermittelt zwei kulturelle Traditionen - eine abendländische und eine afrikanischen Ursprungs - in Haiti gegenüber, wobei der wohlhabende Vater, an der ersteren orientiert, die schwarze Kultur aus seinem Bereich verdrängen, verjagen möchte.

Von Beginn an sind wir mit Mechanismen der Unterdrückung und des Ausschlusses konfrontiert. Allerdings werden wir bald erfahren, dass ebenso Man Bo wie auch der jüngere Bruder des Vaters, Onkel Héraclès, gleichsam als Brücken den Kontakt der jungen Protagonistin mit dieser anderen, aus dem Bürgertum ausgeschlossenen Welt Haitis herstellen. Sie eröffnen ihr damit eine Möglichkeit der Selbstbestimmung und Selbst(er)findung, die nicht über die Worte, sondern über die Sprache des Körper-Leibs zu sich kommt. Es sind Bereiche einer eigenen Kultur, die auf Haiti wie im benachbarten Kuba erst in der ersten Hälfte des 20. Jahrhunderts - und damit in der Epoche der historischen Avantgarden - von Anthropologen wie Fernando Ortiz wissenschaftlich erforscht und zunehmend zu einem wichtigen Bestandteil eigener Kultur gemacht wurden.

Die Zentralstellung des Eingangsbildes wird bereits im zweiten Kapitel reflektiert und hervorgehoben. Es geht um die Frage, wie das einem kleinen, aber führenden Teil der haitianischen Gesellschaft Fremde in das Eigene miteinbezogen und in ein Eigenes verwandelt werden kann. Durch die große Distanz zwischen erzählter Zeit (die vierziger Jahre) und Erzählzeit (die neunziger Jahre) ergibt sich ein Abstand, der metadiskursive Reflexionen notwendig hervorbringt. Daher wird die Zentralstellung des Incipit zum einen sicherlich präzise als „In medias resTechnik“ beschrieben, insoweit wir in der Tat nicht mit dem Anfang oder dem Ende, sondern mit einer mittigen, entscheidenden Szene beginnen. Zum anderen bedeutet die gesamte Anlage aber auch, dass alle Erzählfäden von hier ausgehen und zugleich auch dorthin zurückkehren müssen.

Konstruktiv wird dies in den Schlussworten des Romans in die Tat umgesetzt. Ich möchte Ihnen diese Kreisstruktur gerne anhand dieses letzten Absatzes von Dans la maison du père vor Augen führen:

Die ersten Trommelwirbel steigen aus dem Bauch der Erde auf. Jetzt bin ich alleine inmitten von Schatten und Düften. Mir gegenüber gibt es eine solide gepflanzte Akazie, welche der Mond liebevoll betastet. Zu meinen Füßen schimmern gelbliche Lichter unter den eng 
aneinander gepressten Blechdächern. Und etwas weiter liegt der Garten, wo ich, in meinem blauen Kleid ins Gras gebettet, zu existieren anfing. ${ }^{23}$

In diesem dreiunddreißigsten Kapitel werden im Schlussabschnitt bis in die Wortwahl hinein noch einmal Formulierungen aufgenommen, die wir am Eingang des Romans kennengelernt hatten. Die für den Roman insgesamt zentrale Metaphorik des Bauches, die unter anderem auf Afrika als heißen und turbulenten Bauch der Menschheit, auf das Meer mit seinem Bauch voller Tiere und andere Beispiele übertragen worden war, wird in dieser Schlusspassage auf die Erde bezogen und mit dem Rhythmus der Trommeln verbunden. Offenkundig gibt es nicht nur eine territorialisierende, das heißt eine de- und reterritorialisierende Bewegung im Roman, sondern auch eine tellurische Dimension, die unzweifelhaft das gesamte Romangeschehen, aber auch die Metaphern-Welt des Romans quert. Zugleich zeigt sich, dass wir es hier mit den letzten Reflexen eines Sonnenuntergangs zu tun haben, der auf ein Leben fällt, das wieder zu seinem Ausgangspunkt in das Haus des Vaters zurückgekehrt ist.

Dabei lassen die vieldeutigen Formulierungen des Schlusssatzes eine Beziehung sowohl zum gesamten Romangeschehen als auch zur materiellen Existenz des Romans zu, so dass wir es hier ebenfalls mit einer verdoppelten metadiskursiven Passage zu tun haben. Denn in ihr reflektiert die Existenz der Protagonistin natürlich auch den Beginn ihrer Existenz im Roman und antizipiert zugleich ihr Ende - und das Ende des Romans. Die Dimension der Liebe wird freilich von der menschlichen auf eine ,natürlich-astrale` Ebene projiziert, wird doch das männliche Element der in der Erde steckenden Akazie von der Möndin („la lune“) befingert und durchwühlt (,fouiller“). Dafür aber ist für die Protagonistin selbst kein Platz mehr: Ihr Leben sind ihre Worte, Gedanken und Erinnerungen, die sie mittlerweile allein, in der Einsamkeit ihrer von Schatten und Düften umgebenen Existenz entwickelt.

Die starke Bindung der Tochter an den Vater, diesem „héros magnifique et lointain“, der er später nicht mehr sein sollte, zeichnet sich am Rande eines Gesprächs zwischen beiden ab, das am Vorabend des Abzugs der US-amerikanischen Truppen im August 1934 aus Haiti angesiedelt ist. Der Vater vertraut der kleinen Tochter an, sie sei auf dem besten Wege, zu seiner Königin zu werden, seiner „reine“. Am Rande taucht bereits eine hübsche Frau mit Schirmchen auf, die später im Roman noch mehrfach erscheinen wird und sicherlich darauf verweist, dass die Beziehung des Vaters zur Mutter nicht mehr intakt und stabil ist. Denn der Vater ist ausgerechnet am dreißigsten Geburtstag seiner Frau, an

23 Lahens, Yanick: Dans la maison du père, S. 155. 
der diese - um mit Balzac zu sprechen - zur „femme de trente ans“ wird, zum weiblichen Geschlecht in jüngeren Jahren hingezogen. Die Tochter aber benötigt noch diese Hand des Vaters, die sie doch später - wie wir dies in der Eingangsszene sahen - ohrfeigen sollte. In diesen beiden Situationen um die Hand der Tochter wird im Grunde bereits die ganze Ambivalenz nicht allein dieser Situation, sondern der gesamten Vater-Tochter-Beziehung deutlich erkennbar.

Das Verhältnis zur Mutter ist in der frühen Kindheit liebevoll und ungetrübt; doch bald schon haben sich die beiden nichts mehr zu sagen. Die Mutter bleibt gleichsam zurück und verschwindet hinter dem Horizont. In die abgeschlossene kleinbürgerliche Welt des Hauses von Anthénor Bienaimé dringt gleichwohl die Außenwelt ein. Dies erfolgt nicht nur in Gestalt Man Bos, die gleichsam die schwarzen Kulturen und das Voodoo Haitis einblendet, sondern auch mit Man Lolo, einer kaum sprachfähigen Bettlerin, der Man Bo die Essensreste gibt und gegen deren Gestank die Ich-Erzählerin ankämpft, ohne doch der Faszination durch eine Figur zu entgehen, die wie aus einer anderen Welt stammt.

Denn mit Man Lolo kommt die absolute Armut, das unvorstellbare Elend und Dahinvegetieren einer ganzen Gruppe der haitianischen Gesellschaft in das Haus des Vaters und damit in die Literatur. Auf diese Weise wird in das Haus selbst auch eine soziale Pyramide eingeblendet, welche die Position der bürgerlichen und letztlich gutsituierten Familie in einen größeren sozialen Zusammenhang einordnet. Das Bild der verarmten und verelendeten Alten verfolgt Alice Bienaimé noch lange bis in ihre Träume. Und der Auftritt Man Lolos ermöglicht den Übergang zur Beschreibung des Hinterhofes, der das eigentliche Herrschaftsgebiet Man Bos darstellt. $^{24}$

Gleichzeitig wird anhand dieser Passagen deutlich, dass zwar die Welt des Vaters mit jener seines jüngeren Bruders Héraclès oder jener Man Bos nur vermeintlich wenige Berührungspunkte aufweist, dass aber bei genauerer Betrachtung die Familie doch wesentlich stärker mit durchaus heterogenen kulturellen Formen verzahnt ist, als es der Vater zunächst wahrhaben will. Oft bemerken wir, wie das Verdrängte, Marginalisierte und Ausgeschiedene wiederkehrt. Und wie jede Wiederkehr des Verdrängten erfolgt diese Rückkehr mit Macht und an Stellen, an denen man es nicht vermutet hätte. Dies mag die schroffe, alles unterdrückende Reaktion des Vaters in der Eingangsszene auf das Eindringen marginalisierter afrohaitianischer Kulte in den Körper der Protagonistin erklären.

Denn als seine eigene Tochter die Grenze zur anderen, scheinbar fremden, nicht-abendländischen Kultur überspringt, indem sie zugleich die Grenze vom Innen- zum Außenraum, zum Garten und Hinterhof quert, reagiert der erboste

24 Lahens, Yanick: Dans la maison du père, S. 31. 
Vater mit Unterdrückung und Ausschlussmechanismen. Er tut dies auf dieselbe Weise, wie in den vierziger Jahren eine „Campagne anti-superstitieuse“ auf Haiti mit polizeilicher Gewalt und einer Vielzahl von Unterdrückungsmaßnahmen zur ,Modernisierung“ der haitianischen Gesellschaft durchgeführt wurde. Selbst Onkel Héraclès, aus gutem Hause stammend, wird einmal von zwei Gendarmen aufgesucht, die ihn auf Grund seiner fortgesetzten Kontakte zu einer VoodooPriesterin und zu Gemeinschaften afrohaitianischer Kulte und Riten mit Gefängnis bedrohen. Davor schützt ihn allerdings seine Zugehörigkeit zur sozial besser gestellten, freilich kleinbürgerlichen Familie des Vaters der Protagonistin. Die Unterdrückungsmechanismen sind bereits vor Beginn der Duvalier-Diktatur ubiquitär. Und die Familienstruktur lässt sich sehr wohl als verkleinertes Strukturmodell, als „modèle réduit“ - wie Claude Lévi-Strauss sagen würde - einer patriarchalen Gesellschaft verstehen, aus der die Ich-Erzählerin auszubrechen versucht.

Diese ist zugleich eine von außen abhängige und doch mit dem Außen kommunizierende Gemeinschaft, die - wie alle karibischen Gesellschaften - grundlegend durch vier Jahrhunderte der Sklaverei und nahezu fünf Jahrhunderte des Kolonialismus geprägt wurde. Daraus erklärt sich ein sehr wohl ambivalentes Verhältnis zum Meer, wie es sich in vielen Texten aus der Karibik - selbst noch in Reinaldo Arenas' Roman Otra vez el mar - ausdrückt. Ich möchte Ihnen gerne eine Passage vor Augen führen, die mir diese Ambivalenz sehr charakteristisch zum Ausdruck zu bringen scheint:

Auf dieser Insel haben wir das Meer niemals sonderlich geliebt, waren wir doch davon überzeugt, dass es uns alles Unglück gebracht habe. So bin ich in jenem Sommer nur einoder zweimal zum Baden ans Meer gegangen, doch habe ich lange Zeit sein Rauschen am Tag und sein verstörtes Klagen an den Abenden imaginiert, wie es in den dichten Nächten heranrollt. Ich liebte es, entlang der Spitzen der Algen im Sand zu laufen und zu fühlen, wie das Meer mir die Füße leckte. Ich liebte das Meer wie den Tanz, ich liebte das körperliche Risiko und die Lust. Ich liebte seine Mysterien aus Schaum, aus Salz und aus Wasser. Mit großen Augen träumte ich von seiner wunderlichen und in der Ferne gewalttätigen Unordnung. Von seiner so bitteren Poesie. Von seinem Bauch voller Wasser, mit allen Arten lebendiger und toter Tiere gefüllt, von alten abgedrifteten Karkassen, von feinem Treibsand, von Algen in allen Farben, von seltsamen Korallen. Die Vorstellung vom Leben und vom Tode in diesem Wasserbauch der Welt wurde mir zu einer wohltuenden Träumerei, die mich verzauberte. [...] Weit vom Meer entfernt, vertraute ich oft dem Flusse Artibonite die Geheimnisse an, die ich ihm bestimmte, sicher wie ich war, dass er sie in den großen blauen Abgrund tragen würde. ${ }^{25}$

25 Lahens, Yanick: Dans la maison du père, S. 73. 
Die fundamentale Ambivalenz bei der Deutung des Meeres tritt in den Worten der Ich-Erzählerin deutlich hervor. Denn in dieser Passage sind die unterschiedlichsten Eigenschaften und Elemente des Meeres zusammengepackt. Da ist zum einen die instinktive Angst, die aus der geschichtlichen Erfahrung herrührt, der zufolge stets die Eroberer und Herrscher über das Meer auf die Insel kamen oder aber die Sklaven mit Sklavenschiffen aus weit entfernten Gebieten in Afrika auf diese karibische Insel Hispaniola verschleppt wurden. Wie wäre all dies zu vergessen, einfach ungeschehen zu machen? Da ist zum anderen die Dimension des Lebens, die in der Bauchmetaphorik einmal mehr eine Körpermetaphorik auf einen Teil des Planeten projiziert, der zugleich auch für die Fruchtbarkeit steht. Leben und Tod sind im Bauch des Meeres, sind im Schoße des Meeres in gleichem Maße präsent und spiegeln sich in der klanglichen Gegenwart der See bei Tag und in der Nacht.

Zugleich bildet die blaue Fläche und Tiefe des Meeres den Ort eines Abgrunds, stellvertretend für den Tod, der in seinen Zyklen jedoch immer mit dem Leben verbunden ist. Ebbe und Flut, Tag und Nacht, Leben und Tod: Die ewigen Zyklen des Meeres verkörpern sich in diesem Bauch, der für das immer wieder durchbrechende Lebensprinzip steht, das ohne den Tod nicht denkbar ist. Die Wellen des Meeres rollen mit ihren Mysterien heran, künden von den Botschaften, die für die Menschen nicht immer leicht zu verstehen sind. Denn das Wasser birgt auch Rätsel und Geheimnisse, welche die Protagonistin dem ins Meer mündenden Fluss anvertraut - Geheimnisse tief im Bauch des Meeres geborgen, aufbewahrt für ein späteres Erinnern ...

Denn nicht zuletzt ist das Meer - wie so oft in den Literaturen der Welt - der Ort der Erinnerung, jenes Element, das all diese Erinnerungen in sich aufnimmt und speichert, vielleicht auch nie mehr aus seinem Inneren, aus seinem Bauch, entlässt, aber doch mit seiner Präsenz den Rhythmus dieser Bewegungen des Lebens und des Todes vorführt. Das Meer ist ein Speicher von Vergangenheiten, aber auch von Zukünften: Es führt zurück in der Zeit, aber auch vorwärts. Dies ist eine literarisch sehr schön gestaltete Passage, die organisch in die Entwicklung des Lebens des jungen Mädchens Alice Bienaimé eingebaut wird, wobei sich die ständige Bewegung des Meeres und des Meereskörpers mit seinen Rhythmen hier mit dem Rhythmus des Tanzes und des Tanzens verbinden. So wird der Tanz gleichsam aus der Bewegung am Meer zur Verkörperung elementarer Kräfte und Elemente unseres Lebens, unseres Todes, unserer Wiedergeburt und unseres ganzen Planeten. In diesen Bewegungen scheint das ökologische Zusammenleben, scheint die fundamentale Konvivenz auf, welche die Menschen mit den Tieren, den Pflanzen, dem Sand und den Elementen unserer Erde verbindet. Dies ist eine grundlegende Dimension, die von Anfang an in den Literaturen der Welt, 
im Gilgamesch-Epos wie im Shi Jing, im poetischen Gesang der Erde allgegenwärtig war. ${ }^{26}$

Wie aber äußert sich dies auf Ebene des menschlichen Körper-Leibes, der menschlichen Bewegungen und Choreographien? Mir scheint an dieser Stelle entscheidend, dass es nicht der „Tanz der Engel“ - wie es im Roman heißt -, also die erste Liebesnacht ist, die den Körper der jungen Frau endgültig befreit und sie auch räumlich freisetzt, sondern ein Tanz in der Tanzgruppe von Madame Boural, die sich eine Choreographie für einen heiligen Brauttanz ausgedacht hatte. Am Anfang dieses Tanzes steht erneut der Bezug zum Boden, der über die nackten Füße hergestellt wird, ganz wie im Garten der Eingangsszene des Romans, wo sich die Ich-Erzählerin instinktiv Schühchen und Söckchen auszog. Auch hier sollten wir uns eine längere Passage vornehmen:

Alles begann, als meine nackten Füße das Glatte des Fußbodens berührten. Als ich meine Angst durchmaß wie ein Jongleur einen Feuerkreis. In einer totalen Entäußerung. So habe ich erst einmal alles verloren, ohne Verbindung, ohne Grund, ohne Hoffnung, ohne irgendjemanden, ohne irgendetwas hinter mir. Und je mehr ich auf diesen unbekannten Ort zugehe, umso mehr verliere ich die Sinne und die Zeichen. Ich befinde mich in einer Panik nicht mehr des Verlustes, sondern dieser neuen Dinge und dieser plötzlichen Metamorphosen meines sich ausbreitenden Lebens, meiner sich so weit erstreckenden Territorien ... Ich lächele, ich beweine dieses Leben, das ich nicht kenne. Widerstandslos lasse ich es vorübergehen, trete ein in sein Funkeln. Und plötzlich, ohne Vorsicht zu schreien, öffnet sich mein Körper und das Unbekannte geht ein in einen Abgrund wie ein Nordwind, der anhebt, wie ein Augustgewitter, das die alte Kalebasse des Himmels sprengt. Jetzt steigt mir der Körper wie Rum in den Kopf und fängt an allen Enden Feuer. Das Unbekannte kommt aus der Tiefe der Zeitalter, aus der Tiefe der Jahrhunderte, aus dem Geruch nach Feuer und Blut, das die Wut in großen Mengen verteilt, vom Lachen der Vögel, von den Kindern, von gegen den Mord aufgestachelten Horden, von den Wimpern, die unter den Sternen klimpern, von der schrecklichen Freiheit der Sterbenden, vom Reiseschlaf der Frauen, von Worten, die von Männern ohne jede Vorsicht ausgesprochen werden. Der Körper der jungen Vermählten sagte all dies und mehr noch. Dieser Körper war eine ehrwürdige, vergessene Weisheit, die älter war als Man Bo, älter als die Vorfahren in den Plantagen, älter als alle Frauen in der Genesis, als Rachel, Rebecca, älter als die Göttin Hottento, älter als Ayizan, die Mutter aller Iwa. Ich war sehr weit gegangen, so weit, dass mir allein der Tod als ein Ende einen solchen Höhepunkt hätte anbieten können, ohne jeden Fall. Jeder Augenblick, der diesem hier folgte, wäre fortan hohler und leerer. ${ }^{27}$

26 Vgl. hierzu Ette, Ottmar: La lírica como movimiento condensado: miniaturización y archipelización en la poesía. In: Ette, Ottmar / Prieto, Julio (Hg.): Poéticas del presente. Perspectivas críticas sobre poesía hispanoamericana contemporánea. Madrid - Frankfurt am Main: Iberoamericana - Vervuert 2016, S. 33-69.

27 Lahens, Yanick: Dans la maison du père, S. $139 \mathrm{f}$. 
Wir wohnen einer zweiten Geburt bei. Der Körper der Tanzenden erscheint in dieser komplexen Passage als etwas, das wie die Literaturen der Welt aus den Tiefen der Zeit kommt und die Jahrhunderte durchquert, als ein Medium, in welchem sich - wie in Jorge Luis Borges’ „Aleph“ - alle Zeiten ein Stelldichein geben, ohne sich doch miteinander zu vermischen. In ihm ist eine Weisheit gegenwärtig, die nicht nur alle Zeiten, sondern auch alle Kulturen durchquert und aus der Tiefe des Mensch-Seins kommt. In diesem langen Zitat klingt am Ende wieder das Eingangsthema des haitianischen Tanzes an, indem auf physische Weise alle Zeiten, alle Erfahrungen in einem einzigen Augenblick der Erleuchtung präsent sind, in der Allgegenwart aller Geschichten und aller Weisheit bis ans Ende der Zeit, aufgehoben im tanzenden Körper-Leib.

Das Medium für alles Erleben, alles Erfahren, ist also der Körper: der Körper einer Frau, die die Rolle einer jungen Vermählten spielt. Doch sie bringt zugleich alle anderen Frauenrollen, die der Dienerin Man Bo, der Frauen aus der Genesis, der afrikanischen Gottheiten und der Göttinnen-Mutter Ayizin, quer durch die christlichen, afrikanischen, haitianischen Voodoo-Kulte und Religionen, alle transkulturellen und transhistorischen Körper also, in ihrem Körper zum Sprechen, zum Klingen, zum Schwingen. Damit wird zugleich eine Körper-Logik entfaltet, in der der Körper in den Kopf hochsteigt und alle Sinne umfasst, vor allem aber seine eigene Logik zum Tragen bringt. Die körperlichen Bewegungen werden zu einer eigenen Sprache, die letztlich auch zur Trennung der Tänzerin von ihrem geliebten Edgard führt und zum Verlassen Haitis im letzten der dreiunddreißig Kapitel des Romans, das sich unmittelbar an dieses zweiunddreißigste Kapitel anschließt.

Die Körper-Logik wird zugleich zu einer Filiation innerhalb verschiedener Stimmen von Frauen aller Zeiten: Der Kontakt mit dem Boden führt zur Erdung, indem auch die Erdgottheiten wieder mit dem eigenen Leben und allen anderen Leben verbunden werden. Auch diesbezüglich ist der Körper der erleuchteten Tänzerin vergleichbar mit den Literaturen der Welt: Er enthält ein Lebenswissen, das nicht nur aus dem einen kleinen Individuum kommt, sondern sich das Wissen, das Lebenswissen aller Stimmen erschließt und zugänglich macht. So kommt in einem Körper das Leben der vielen zum Vorschein und zu einem Ausdruck, der jenseits der Sprache liegt, und doch von der Sprache der Literatur als Lebenswissen dargestellt und vorgeführt werden kann. Wir haben es in dieser Passage mit einer beeindruckenden literarischen Szene $\mathrm{zu}$ tun, die sich wie ein kleines „poème en prose“ lesen lässt, vor allem aber eine Apologie des tanzenden weiblichen Körpers und der ästhetischen Darstellungskraft der Literatur selbst ist.

Der Tanz der haitianischen Ich-Erzählerin, die sehr wohl des literarischen Wortes mächtig ist, rückt somit Ausdrucksfähigkeiten und Logiken in den Vorder- 
grund, die zunächst nicht-verbaler Natur sind. Zugleich aber wird deutlich, dass diese Ausdrucksfähigkeiten transhistorisch existieren und sich hauptsächlich aus drei kulturellen Strängen speisen: zunächst der abendländischen, jüdischchristlichen Tradition, für die die Genesis und der Verweis auf die biblischen Stammmütter steht; zweitens die afrikanischen Traditionen, für die hier ebenfalls zahlreiche Quellen genannt werden. Und drittens schließlich die spezifisch haitianische Tradition, die auf synkretistische Weise die abendländische mit der afrikanischen Tradition auf amerikanischem Boden verbindet. Die Territorien der tanzenden Ich-Erzählerin werden weit, sehr weit: Sie umfassen transareal weite Kontinente und Insel-Welten auf unserem Planeten.

Diese Traditionen sind in den Bewegungen des Körpers gespeichert, eines Körper-Leibes in seinem Leib-Sein und Körper-Haben, von dem der Tanz als uralte Ausdrucksmöglichkeit des Menschen vollständig Besitz ergriffen hat. So bekommt die Geschichte der Menschheit eine künstlerische Ausdrucksform, die den Körper als Objekt bei weitem übersteigt und das Körper-Haben in ein grundlegendes Leib-Sein verwandelt, in dem die Tänzerin zu sich selbst findet, gerade weil sie nicht auf sich selbst beschränkt bleibt. Denn ihr Wesen ist es, viele zu sein, so wie die Literatur stets auf intertextuelle Weise viele unterschiedliche Texte zum Klingen bringt.

Diese Geschichte ist sozusagen in die Lebensgeschichte der Protagonistin ,eingewoben', die ganz wesentlich zu einer Geschichte des Tanzens, der Entäußerung und Befreiung des weiblichen Körper-Leibes wird. Denn es geschieht durch den Tanz, dass die Protagonistin ihr eigenes Leben in die Hände - und die Füße - nehmen kann. Ich möchte Ihnen gerne aus dem letzten, dem dreiunddreißigsten Kapitel einige Passagen zeigen, die belegen, wie sehr der Roman an seinem Ende von allerlei Formen der Flucht, des Exils und der Diaspora geprägt ist. Es zeigt sich, dass das Virus der Zivilisation die Ich-Figur nicht bei den Lehrerinnen befällt, denen sie als Kind ausgeliefert war und die ihr die französische Zivilisation unter Abwertung der haitianischen - für die sie selber standen - einpauken wollten, sondern dass diese Ansteckung viel später auf einer anderen Insel erfolgte, welche fraktal für eine ganze Welt steht - die Insel Manhattan:

Ich bin in New York am 2. September 1948 angekommen. Sehr schnell wurde ich in dieser gigantischen, bösartigen und funkelnden Stadt mir selbst überlassen, frei, mein Leben zu tanzen, frei, nach Belieben etwas zu lieben oder abzulehnen, mein Herz von all seinen Verknotungen befreit. Und es war in dieser Stadt und nicht bei den Fräuleins Védin, dass ich mir mein Virus einer Zivilisierten einfing, dieses eine Viertelsekunde lang empfundene Gefühl der Leere, der Lebensunfähigkeit, das bisweilen bis zur Erstickung ging. [...]

Edgard hat die Insel 1962 verlassen. Mit der Zeit schützte mich der Tanz vor der Stärke dieser brennenden und schweigsamen Beziehung. In seinen letzten Briefen sprach er von der langsam in ihm hochsteigenden Angst, von den ersten Wachtposten und ihrem Geknister, 
das die Nacht zerriss, von Bohemia, der Zeitschrift der jungen kubanischen Revolutionäre. Er vergaß nie, den bleiernen Estrich zu betonen, der auf die Insel niedergegangen war, auf die Miliz, in blauer Uniform mit schwarzer Brille, auf den Straßen marschierend oder im DKW fahrend. Sein Freund Benoît, sein Bruder, war festgenommen worden, und er sah ihn niemals wieder. Edgard lebt heute irgendwo zwischen Europa und Amerika inmitten seiner Gemälde mit Tonnen von Alkohol in den Venen und Frauenkörpern in den Knochen. [...] Onkel Héraclès hat eine junge zerbrechliche Frau geheiratet, die in ihren Händen sein zerbrochenes Leben birgt. Er lebt heute in Finnland in einem Land des Schnees, fernab der Armen, fernab der Schwarzen und ihrer ganzen Last an Problemen. Von den Schwarzen spricht er, indem er die Bücher befragt. Für die Armen spendet er Geld, sobald die UNICEF oder Save the Children rufen. Er wollte Haiti vergessen, dieses Land, wo es - wie er mir eines Tages schrieb - keinen Platz mehr für Leute gibt, die ganz einfach leben wollen. Stets steht man Schatten gegenüber. ${ }^{28}$

Die zurückblickenden Reflexionen der Ich-Erzählerin bringen alle Reflexe zerbrochener haitianischer Leben zusammen. Die Protagonisten des Romans sind entweder tot oder in alle Winde zerstreut. Sie leben fern von Haiti, das in eine der schlimmsten Unterdrückungsmechanismen verfallen ist und zwischen 1957 und 1986 in der Hand der Duvaliers eine der schlimmsten Diktaturen erleidet. Die gefürchteten Tontons Macoutes der Duvaliers haben auch auf den Seiten dieses Bildungsromans ihre blutigen Spuren hinterlassen.

Bis heute halten die Folgen der einander ablösenden Diktaturen auf Haiti an, noch heute sind es gerade die Haitianer, welche die unmenschlichsten Lebensbedingungen auf ihrer Teilinsel erleiden müssen. Doch die Erinnerungen Haitis reichen weiter zurück, denn seit den Reparationszahlungen an Frankreich im Zuge der Haitianischen Revolution stürzte das Land von einer Krise in die andere und vermochte es nicht, sich wirtschaftlich und sozial dauerhaft zu erholen. Zudem ist die frankophone Welt der Karibik in höchstem Maße in zwei Welten gespalten: die neokolonial-departementalisierte Welt von Guadeloupe und Martinique, wo in den französischen Überseedepartements mittlerweile längst der Euro rollt, und jene andere Welt der ehemals reichsten Kolonie des gesamten Planeten, Saint-Domingue, wo gänzlich andere Maßstäbe herrschen. Jede Krise, auch die aktuelle Corona-Krise, trifft die Einwohner dort am schlimmsten, denn es gibt keinerlei soziales oder medizinisches Netz, das die Folgen zumindest abfedern könnte. In der westlichen Welt ist Haiti aus den Nachrichten verbannt, nur von den schlimmsten Katastrophen gibt es noch Kurzberichte. Seit der Haitianischen Revolution, seit dem erfolgreichen Aufstand schwarzer Sklavinnen und Sklaven gegen ihre weißen Herren, wurde Haiti Stück für Stück aus allen Netzwerken verbannt und ist heute weitestgehend seinem Schicksal überlassen und vergessen.

28 Lahens, Yanick: Dans la maison du père, S. 149 f. 
Die Literatur bietet den heute wohl besten Zugang zu Geschichte und Leben dieses Landes, das zwar im geographischen Herzen, aber im Schatten der westlichen Hemisphäre liegt. Yanick Lahens konnte ihren Roman in einem Pariser Verlag, Le Serpent à Plumes, veröffentlichen. Da diese Ausgabe mit 85 Francs oder knapp 13 Euros aber viel zu teuer für die wenigen Leser*innen auf Haiti ist, hat sie vom Verlag - wie in solchen Fällen üblich - die Möglichkeit ausgehandelt, ihr Buch bei einem haitianischen Verlag parallel zu publizieren. Dort liegt der Band dann in einer einfachen und für Haitianer erschwinglichen, aber nochmals durchgesehenen und leicht veränderten Fassung vor.

Ein Wort noch zur Literatur oder den Literaturen Haitis, dieses Landes mit einer großen und bisweilen großartigen Geschichte: Die haitianische Literatur ist allen Stürmen, Krisen und Bewegungen ausgesetzt, die der gesamten Karibik im Zuge ihrer Abhängigkeit stets ihr wechselndes und zugleich doch immer gleiches Antlitz gaben. Nur dass sich diese Bewegungen in der haitianischen Literatur noch stärker niederschlugen als in den Literaturen der gesamten karibischen Area. Diese Literatur verkörpert - vergleichbar mit der Literatur Kubas - geradezu paradigmatisch eine transterritoriale und mehr noch radikal transareale Literatur, die sich jenseits des Territorialen ihre eigenen Landschaften, ihre eigenen Beziehungen, ihre eigenen Themen erstritten hat - unabhängig davon, ob ihre Autorinnen und Autoren auf der Insel oder fernab in Kanada, Finnland, Deutschland oder den USA schreiben. Bisweilen führen große Tagungen all diese Autor*innen zumindest kurz wieder zusammen.

So gibt es eine bisweilen verblüffende Einheit und zugleich fundamentale Vielheit innerhalb der haitianischen Literatur, in welcher einzelne Schriftsteller^innen längst damit begonnen haben - ähnlich wie im kubanischen Fall -, in den Sprachen ihrer Gast- und Aufenthaltsländer zu schreiben. Kuba und Haiti gehören aus unterschiedlichen Gründen heute zweifellos zu jenen Ländern, deren Literaturen im vollen Wortsinn zu Literaturen ohne festen Wohnsitz geworden sind. Denn auch eine Nationalliteratur kann zu einer Literatur ohne festen Wohnsitz werden - ganz so, wie wir es derzeit etwa in Syrien oder im Libanon (für dessen Literaturen wir ja zwei Beispiele in diese Vorlesung aufnehmen durften) beobachten können.

Eine solche Einschätzung der haitianischen Literatur hat auf meine Rückfrage Yanick Lahens im März 2002 anlässlich des in Berlin geführten Interviews bestätigt. Auf die Frage, ob im Rahmen der hier geschilderten Situation die haitianische Literatur - ähnlich wie die kubanische - einen Startvorteil besitze und auf die kommenden Entwicklungen vielleicht besser und früher vorbereitet sei, antwortete sie wie folgt: 
Ich sage gewöhnlich, dass wir eine Länge Vorsprung haben. Warum? Weil in der Tat das, was mit dieser Literatur geschehen wird, die man aus Bequemlichkeit die Literatur von draußen, aus der Diaspora oder dem Exil nennt, eine Reihe sich differenziert stellender Probleme betrifft: Erstens die identitäre Problematik, die sich angesichts der haitianischen Geschichte sehr stark stellt. Ich glaube, dass man die Problematik der Identität ein wenig aus ihrer Abgeschlossenheit herausholen wird. Die Identität wird viel offener sein: Wenn jemand wie Emile Olivier sagt „Ich bin Kanadier am Tag, Haitianer bei Nacht“, dann kann einem schon klar werden, dass die Identität nichts Unbewegliches und Stabiles ist. Sie ist etwas, das sich bewegen kann. Sie bewegt sich in der Zeit, sie bewegt sich auch im Raum. Also schon hier gibt es eine Erneuerung der Problematik, die von Interesse ist. Zweitens glaube ich auch, dass dies - aber das ist meine persönliche Theorie - die Bewertung der Gattung vorantreiben wird. Man wird sehen, dass viele von denen, die aufgebrochen sind, Dichter waren, doch kommen sie in einem Kontext an, der die Entfaltung des Romans als Gattung der Moderne begünstigt. Und der größte Teil der haitianischen Romane zwischen 1970 und 1980 - heute ist es ein wenig anders - wurde im Ausland geschrieben. Bestimmte grundlegende Dinge haben sich also aus diesem Blickwinkel verändert. Ohne die Tatsache zu berücksichtigen, dass der Status des Schriftstellers in den kulturellen Räumen der großen Metropolen nicht derselbe ist, dass hier die Möglichkeiten aus vielerlei Gründen größer sind. Halten wir auch fest, dass die zweite Generation an Schriftstellern das Exil mit geringerem Schmerz durchleben wird und sie sich als moderne Nomaden betrachten werden. Das Exil verwandelt sich in ein Umherirren. Sie deplatzieren sich überallhin, mitsamt ihrer Wurzeln. Und wir befinden uns näher an den Theorien von Glissant über die rhizomatische Identität. Die dritte Generation wird sogar in einer Fremdsprache schreiben. Was uns auch dazu zwingt, den Begriff der Nationalliteratur und des nationalen Erbes neu zu denken. Die erste Exilgeneration und die Migranten der anderen Generationen werden die Problematik einer Nationalliteratur explodieren lassen. Heute kann man sich die Frage stellen: Was ist, wenn wir die haitianische Literatur heranziehen, eine Nationalliteratur? ${ }^{29}$

Die Frage nach der Nationalliteratur ist damit in fundamentaler Weise gestellt. Und in der Tat: Aus dem Blickwinkel der Literaturen Europas stellt sie sich mit einer wesentlich geringeren Dynamik und Virulenz. ${ }^{30}$ Wie sinnvoll ist es in Zusammenhang mit dem viellogischen System der Literaturen der Welt noch, von Nationalliteraturen zu sprechen, solange man sich auf das Studium dieser einen Nationalliteratur beschränkt? Hatte nicht der deutsche Romanist Erich Auerbach verlauten lassen, dass ein Provenzalist, der sich ausschließlich mit provenzalischer Literatur beschäftigt, auch kein Provenzalist mehr sei? Bitte bekommen

29 Lahens, Yanick, im Interview mit Ottmar Ette: „Faire éclater la problématique d’une littérature nationale“, S. $226 \mathrm{f}$.

30 Vgl. hierzu Lützeler, Paul Michael: Zur Zukunft der Nationalphilologien: Europäische Kontexte und weltliterarische Aspekte. In: Internationales Archiv für Sozialwissenschaften XL, 1 (2020), S. 69-83. 
Sie jetzt keine Angst, wenn Sie etwa Germanistik studieren: Ich möchte Ihnen als Romanist und Komparatist Ihren Seins-Grund und schon gar nicht Ihr Interesse an deutschsprachiger Literatur nehmen! Aber wie sinnvoll ist es noch, eine Germanistik zu betreiben, die sich ausschließlich mit der deutschen Literatur beschäftigt? Bis jetzt besteht das System der Nationalliteraturen und der Nationalphilologien noch fort. Aber es wird in diesem Bereich in nicht allzu ferner Zukunft gewaltige Veränderungen geben. In diesem Sinne, so ließe sich in der Tat mit Yanick Lahens sagen, ist uns Haiti voraus.

Sicherlich: Letzteres befindet - ähnlich wie Kuba - in einer extremen Situation, hält sich doch ein Gutteil seiner Künstler*innen und Autor*innen außerhalb der Insel auf oder war zumindest zeitweise im Exil oder der Diaspora. Aber bei genauerem Hinsehen trifft dies für eine nicht geringe Zahl an Ländern und Nationen zu. So zeichnen sich fraglos Entwicklungen ab, die wir auch in anderen Breitengraden sehr gut nachvollziehen können. Ich möchte Ihnen daher in der Folge eine Autorin präsentieren, welche die Problematiken der am Beispiel der haitianischen Literatur ausgeführten Überlegungen auf einen uns sehr nahen Bereich überträgt: eben auf die deutschsprachigen Literaturen. Und damit kommen wir gegen Ende unserer Vorlesung wieder nach Europa zurück. 